\title{
Review Article \\ Mathematical Analysis of Queue with Phase Service: An Overview
}

\author{
Richa Sharma \\ Department of Mathematics, JK Lakshmipat University, Jaipur 302026, India \\ Correspondence should be addressed to Richa Sharma; richasharma@jklu.edu.in
}

Received 22 May 2014; Revised 2 September 2014; Accepted 21 October 2014; Published 10 December 2014

Academic Editor: Shey-Huei Sheu

Copyright (C) 2014 Richa Sharma. This is an open access article distributed under the Creative Commons Attribution License, which permits unrestricted use, distribution, and reproduction in any medium, provided the original work is properly cited.

\begin{abstract}
We discuss various aspects of phase service queueing models. A large number of models have been developed in the area of queueing theory incorporating the concept of phase service. These phase service queueing models have been investigated for resolving the congestion problems of many day-to-day as well as industrial scenarios. In this survey paper, an attempt has been made to review the work done by the prominent researchers on the phase service queues and their applications in several realistic queueing situations. The methodology used by several researchers for solving various phase service queueing models has also been described. We have classified the related literature based on modeling and methodological concepts. The main objective of present paper is to provide relevant information to the system analysts, managers, and industry people who are interested in using queueing theory to model congestion problems wherein the phase type services are prevalent.
\end{abstract}

\section{Introduction}

In congestion situations of day-to-day as well as industrial problems, it has been realized that queueing models with phase service play vital role in depicting and analyzing queueing situations. Our aim in this paper is to provide an overview on the conceptual aspects for the phase service queueing models in different frameworks. In traditional queueing models, all arriving customers/jobs require main service which is to be completed in single phase. In many real time systems the service may be completed in many phases. The concept of optional phase services has been studied by many researchers for improving the grade of service. Sometimes only a few arriving customers require the optional services along with essential service for their satisfaction.

Queueing models with phase service accommodate the real-world situations more closely. The purpose of present paper is to provide overview of queueing models with phase service and its applications in real life queueing problems. The motivation for studying the queueing systems with phase service comes from numerous versatile applications in the performance evaluation and dimensioning of production and manufacturing systems, computer and communication networks, inventory and distribution systems, and so forth.
During the last few decades, attention has been paid increasingly by many researchers in studying the phase service queueing models. Many developments have taken place from time to time in this field and need further research in this regard. Various studies on phase service queueing models have appeared during literature 80's and 90's.

The various applications of phase service queueing models can be made in day-to-day and industrial scenarios which motivate us for studying phase service queue in in different frameworks. For this purpose, we cite an example of the manufacturing systems wherein units proceed through a series of work stations. A machine used to produce a variety of items can be modeled as a single server queue with phase service. Next, we consider the situation Internet and Voice-over-IP (VoIP) protocol. VoIP is an upcoming and demandable technology that enables people to make telephone calls via an IP network such as the internet at very low, or even no cost. In VoIP protocol, the service process consists mainly in transferring the information of caller to another end user. This service process of VoIP is done in three phases: (i) connection establishment, (ii) transferring information, and (iii) accessing differentiated services. The motivation for the phase service queue also comes from some computer and communication networks where single server 
processes the messages in phases with the help of message generation center, which acts as a server and a pacing box, which stores the arriving messages.

Our main purpose in this survey paper is to provide an overview for phase service queueing models and to explore how these results may be helpful for practical problems. We shall report prominent works done on the queueing models with phase service for different scenario. The rest of the paper is structured as follows. Section 2 describes basic definitions and classification of the phase service queueing models. Various methodologies/techniques used for solving phase service queueing models have been discussed in Section 3. Section 4 is devoted to various performance measures for queueing problems with phase service. In Section 5, we review the performance analysis of some notable phase service queueing models developed by researchers in different frameworks. Illustration has been given in Section 6. Finally, conclusion is drawn in Section 7.

\section{Phase Service System}

Queueing system with phase service has received a significant amount of attention of the researchers working in the area of queueing and reliability theory. Phase service queueing models have been studied extensively by many prominent researchers for improving the grade of service due to their wide applicability in many industrial queueing problems areas. Each type of service has its own significant impact on the real time system. In phase service queueing system, all arriving customers are served in phases; out of these some are essential phases of service provided by the server to all arriving customers whereas some are optional services provided by the server to the customers depending upon their choice.

The most common distributions which are frequently used in the real time systems are the exponential and Poisson distributions. In-fact, the exponential distribution is widely accepted because the queueing models having exponential distribution are of practical utility and very easy to be handled. The main target of selecting a proper distribution and estimating their parameters is to provide a tractable analytical model giving a close approximation to the real life system under consideration. Some of shortcomings might be alleviated by creating mixtures of exponential distributions to define more complex distribution wherein the service is provided in phases. Commonly used distributions to depict phase type service are as follows.

2.1. Erlangian Distribution. In many complex queueing situations, Erlangian distribution provides a good starting point for the systems with phases or stages. The density function of Erlangian distribution is given by

$$
f(t)=\frac{(\lambda k)^{k} t^{k-1} \exp (-k \lambda t)}{(k-1) !}, \quad t>0, \lambda>0,
$$

where $k$ is the positive integer. A process with sequential phases gives rise to an Erlangian distribution depending upon whether or not the phases have identical distribution. Erlang

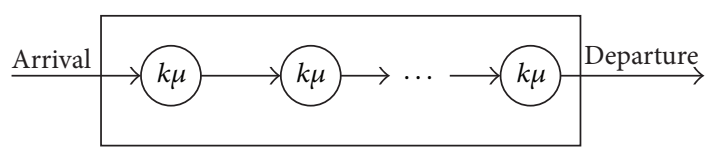

FIGURE 1: Schematic representation of Erlangian service facility with $k$ phases.

distribution has been considered by Adan et al. [1], Wang [2], Wang and Kuo [3], Jain and Agrawal [4], and many others in different frameworks. The design of Erlangian distribution is purely sequential as shown in Figure 1.

To have a look on the performance analysis prediction of Erlangian distributed queueing system, we describe $M / E_{k} / 1$ queueing model in brief (compare to [5]). The customers are assumed to arrive according to Poisson process with rate $\lambda$. The customers are served according to $k$-phase Erlang distribution with mean $1 / k \mu$. Let $P_{0}$ be the probability when there are no customers in the system. Further, we assume that $P_{n, i}$ represents the probability that there are " $n$ " customers in the system and the service of the customer is being rendered in $i(i=1,2, \ldots, k)$ phases. The steady-state equations governing the model are given as follows:

$$
\begin{gathered}
\lambda P_{0}=k \mu P_{1,1}, \\
(\lambda+k \mu) P_{1, k}=k \mu P_{2,1}+\lambda P_{0}, \\
(\lambda+k \mu) P_{1, i}=k \mu P_{1, i+1}, \quad 1 \leq i \leq k-1, \\
(\lambda+k \mu) P_{n, k}=k \mu P_{n+1,1}+\lambda P_{n-1, k}, \quad n \geq 2, \\
(\lambda+k \mu) P_{n, i}=k \mu P_{n, i+1}+\lambda P_{n-1, i}, \\
n \geq 2, \quad 1 \leq i \leq k-1 .
\end{gathered}
$$

Using generating function method, we can solve (2) to obtain the steady state queue size distribution which can be further used to derive various performance indices.

2.2. Hyperexponential Distribution. A hyperexponential distribution with $k$ stage is denoted by $H_{k}$. In hyperexponential distribution, the service facility follows a parallel arrangement as depicted in Figure 2. A mixture of $k(\geq$ 2) independent exponential distributions having probability density function

$$
\begin{array}{r}
f(t)=\sum_{i=1}^{k} \alpha_{i} \lambda_{i} \exp \left(-\lambda_{i} t\right), \\
t>0, \quad \alpha_{i}>0, \quad \lambda_{i}>0, \quad \sum_{i-1}^{k} \alpha_{i}=1
\end{array}
$$

is called a $k$-stage hyperexponential distribution.

Wang et al. [6] suggested optimal control for an infinite and a finite $\mathrm{M} / \mathrm{H}_{2} / 1$ queueing system with removable and non-reliable server. This model was again extended by Wang et al. [7] for $k$-type hyperexponential service time distribution. The optimal control of an $\mathrm{M} / \mathrm{H}_{k} / 1$ queueing system 


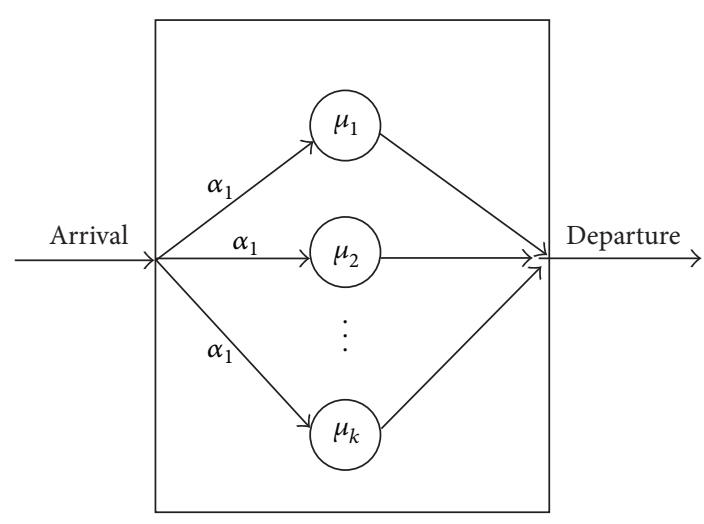

FIGURE 2: Schematic representation of hyperexponential service facility with $k$ phases.

was considered by Wang and Yen [8]. Further, Sharma [9] considered a $\mathrm{M}^{X} / \mathrm{H}_{2} / 1$ queueing system under $N$-policy with vacation and un-reliable server. Now, we proceed to describe the $\mathrm{M} / \mathrm{H}_{k} / 1$ model of Wang and Yen [8]. It is assumed that the customers arrive with parameter $\lambda$ and service times follow $k$-type hyperexponential distribution. Suppose that $\mu_{i}$ is the service rate of $i$ th $(i=1,2, \ldots, k)$ phase service. Let the probability that the next customer to enter service is of type $i$ be $q_{i}(i=1,2, \ldots, k)$ and $\sum_{i=1}^{k} q_{i}=1$.

Let us denote the steady state probabilities as follows:

$P_{(0, n)}$ : Prob. that there are $n(=0,1,2, \ldots, N-1)$ customers in the system when the server is turned off.

$P_{(i, n)}$ : Prob. that there are $n(=1,2, \ldots)$ customers in the system and the customer in service is in phase $i$ $(=1,2, \ldots, k)$ when the server is turned on and in operating state.

The steady state equations for $\mathrm{M} / \mathrm{H}_{k} / 1$ queueing system are constructed as follows:

$$
\begin{gathered}
P_{(0,0)}=P_{(0, n)}, \quad 1 \leq n \leq N-1, \\
\lambda P_{(0,0)}=\sum_{j=1}^{k} \mu_{j} P_{(j, 1)}, \\
\left(\lambda+\mu_{i}\right) P_{(i, 1)}=q_{i} \sum_{j=1}^{k} \mu_{j} P_{(j, 2)}, \quad 1 \leq i \leq k, \\
\left(\lambda+\mu_{i}\right) P_{(i, n)}=\lambda P_{(i, n-1)}+q_{i} \sum_{j=1}^{k} \mu_{j} P_{(j, n+1)}, \\
1 \leq i \leq k, \quad 2 \leq n \leq N-1, \\
\left(\lambda+\mu_{i}\right) P_{(i, N)}=q_{i} \lambda P_{(0, N-1)}+\lambda P_{(i, N-1)}+q_{i} \sum_{j=1}^{k} \mu_{j} P_{(j, N+1)},
\end{gathered}
$$

$$
\begin{array}{r}
\left(\lambda+\mu_{i}\right) P_{(i, n)}=\lambda P_{(i, n-1)}+q_{i} \sum_{j=1}^{k} \mu_{j} P_{(j, n+1)}, \\
1 \leq i \leq k, \quad n \geq N+1 .
\end{array}
$$

Equations (4) can be solved easily using the generating function method to determine the distribution of the number of the customers.

2.3. Phase Type Distribution. The preceding distributions are all special cases of the phase-type distribution. More general arrangements of phase type distributions may be achieved by mixing sequential and parallel arrangements of single phase distributions. The notation " $\mathrm{PH}$ " is used for phase type distribution. This distribution is characterized by a Markov chain with states $1,2, \ldots, k$ (the so called phases) and a transition probability matrix $P$ which is transient. The random variable " $X$ " has a phase-type distribution if $X$ is the total time elapsing from start in the Markov chain till departure from the Markov chain. Further, we can define the phase type distribution as the distribution of absorption times of a certain Markov jumps processes which constitute a class of distribution on the positive real axis which seems to strike a balance between generality and tractability. For more detail, we refer the work of Neuts [10-12] and Asmussen [13].

2.4. Two-Phase Essential Service. Queueing models wherein the server provide two phases of essential service to each customer are known as two-phase essential service queueing model. Such types of queueing situations naturally arise in many real time system namely in manufacturing system wherein the machine producing certain items may require two phases of service in succession. For completing the processing of raw materials, the periodic checking (first phase of service) followed by usual processing (second phase of service) of raw material is required. Kumar and Arumuganathan [14] considered a single server retrial queue with batch arrivals under the assumption that the server provides preliminary first essential service (FES) and second essential service (SES) to all arriving calls.

2.5. Two-Phase Optional Service. In many realistic situations, all jobs demand the second optional service along withfirst essential service (FES). The concept of second optional service was studied by Madan [15]. He considered a model of $\mathrm{M} / \mathrm{G} / 1$ type where the server provides first essential service to all arriving customers and then after, a few customers may demand for a second optional service (SOS). For example, in a cyber café, the customers arrive for utilizing Internet surfing (as FES) but some of them may require scanning of some files (as SOS) also.

2.6. Multiphase Essential Service. In such a queueing system, the server serves the customers in finite number of phases. All these phases are essential for each customer to complete the whole service process. To illustrate, this phenomenon we can cite a clinical physical examination procedure as a doctor's clinic wherein the patient goes through a series of physical 
checkup such as ear, nose and throat examination, blood test, electrocardiogram, eye examination which all are considered as essential phases of service to reach the final decision by any medical doctor to declare a candidate to be fit. Recently, Jain and Agrawal $[16,17]$ examined a batch arrival queueing system with modified Bernoulli vacation under $N$-policy wherein the customer needs $l$-stage of service in succession that is, the first stage service (FSS) is followed by the second stage service (SSS), the second stage service followed by third stage service (TSS) and so on up to $l$-stages of service.

2.7. Multiphase Optional Service. Multioptional phase service queueing models are those in which the server provides the first essential service (FES) to all arriving customers. After the completion of FES, the server renders a second optional service (SOS) with probability $p_{1}\left(0 \leq p_{1} \leq 1\right)$ if someone demands for the same otherwise he leaves the system with complementary probability $\bar{p}_{1}\left(=1-p_{1}\right)$. After the completion of SOS, the customer may demand a third optional service with probability $p_{2}\left(0 \leq p_{2} \leq 1\right)$, or may leave the system with probability $\bar{p}_{2}\left(=1-p_{2}\right)$. In general, the customer may request for any of the $i$ th $(4 \leq i \leq l)$ phase optional services with probability $p_{i-1}$, or may leave the system with probability $\bar{p}_{i-1}\left(=1-p_{i-1}\right)$. For example, in "Malls," generally the customers arrive for watching movie as the first essential service but few of them may demand for other optional services such as shopping, amusements for children, and food in restaurant. Jain and Upadhyaya [18] dealt with unreliable server batch arrival queueing system with essential and multioptional services under $\mathrm{N}$ policy. Using probability generating function technique, they obtained the system size distribution and other performance indices.

\section{Queueing Methodology for Phase Service System}

In many congestion situations, it is very difficult to analyze the performance analysis of queueing system with phase service. Therefore, a wide variety of techniques are used for providing the solution of queueing problems in different frameworks. In Table 1, we have summarized some important classical techniques used by prominent researchers for investigating the queueing models with phase service. Furthermore, we describe some methodological aspects of queueing models with phase service by discussing the wel-established techniques, namely, supplementary variable technique (SVT), probability generating function (PGF), embedded Markov chain (EMC), matrix geometric/matrix method, maximum entropy analysis (MEA) and many others as follows.

3.1. Supplementary Variable Technique (SVT). SVT is an elegant analytical technique which is frequently used for the solution of non-Markovian queueing problems. Using this technique, we can convert a non-Markovian queueing model in Markovian queueing model by introducing one or more supplementary variables. In this approach, the supplementary variables are introduced corresponding to either elapsed time or remaining time of the random variables. The supplementary variables are taken corresponding to service time for the model with general service time whereas for general input model, the supplementary variables are used corresponding to interarrival time. Firstly, SVT was used by Cox [19] to study the M/G/1 queueing system.

In order to explain the use of the SVT, we describe an M/G/1 queue with additional second phase service model which was analyzed by Madan and Baklizi [20]. In such a model, we assume that the customers arrive in the system according to Poisson process with rate $\lambda$. Each arriving customer requires the first essential phase of service and the server also provides additional optional second phase service to the customers who demands for the same. Let $Q$ be the probability when the server is in idle state. Let $P_{i, n}(x)$ be the steady state probability that there are $n(\geq 0)$ customers in the queue excluding one in $i$ th $(=1,2)$ phase of service and the elapsed service time of this customer is $x$. Further, we assume that $R_{i, n}(x)$ denotes the steady state probability that there are $n(\geq 0)$ customers in the queue excluding one customer who is repeating the $i$ th $(=1,2)$ phase of service and the elapsed time for this service is $x$. Let $\mu_{i}(x) d x$ be the conditional probability of completion of $i$ th $(=1,2)$ phase service, then we have

$$
\mu_{i}(x)=\frac{g_{i}(x)}{1-G_{i}(x)}, \quad i=1,2,
$$

where $G_{i}(x)$ be the cumulative distribution function for $i$ th $(=1,2)$ phase service.

Using the supplementary variable technique, we have the following steady state equations:

$$
\begin{aligned}
& \frac{d}{d x} P_{i, n}(x)+\left(\lambda+\mu_{i}(x)\right) P_{i, n}(x)=\lambda P_{i, n-1}(x), \\
& n \geq 1, \quad i=1,2, \\
& \frac{d}{d x} P_{i, 0}(x)+\left(\lambda+\mu_{i}(x)\right) P_{i, 0}(x)=0, \quad i=1,2, \\
& \frac{d}{d x} R_{i, n}(x)+\left(\lambda+\mu_{i}(x)\right) R_{i, n}(x)=\lambda R_{i, n-1}(x), \\
& \frac{d}{d x} R_{i, 0}(x)+\left(\lambda+\mu_{i}(x)\right) R_{i, 0}(x)=0, \quad i=1,2,2, \\
& \lambda Q=\left(1-r_{2}\right) \int_{0}^{\infty} P_{2,0}(x) \mu_{2}(x) d x \\
& +\left(1-r_{1}\right)(1-p) \int_{0}^{\infty} P_{1,0}(x) \mu_{1}(x) d x \\
& +(1-p) \int_{0}^{\infty} R_{1,0}(x) \mu_{1}(x) d x \\
& +\int_{0}^{\infty} R_{2,0}(x) \mu_{2}(x) d x .
\end{aligned}
$$


TABLE 1: Contributions on phase service queueing models using different techniques.

\begin{tabular}{ll}
\hline Techniques & Authors \\
\hline & Rana [73], Murray and Kelton [74], Selvam and Sivasankaran [75], Madan [76, 77], \\
Probability generating function technique & $\begin{array}{l}\text { Choi and Kim [78], Madan et al. [79], Griffiths et al. [80], Ke and Chu [81], Kumar } \\
\text { and Arumuganathan [82], Salehirad and Badmchizadeh [59], Thangaraj and }\end{array}$ \\
& $\begin{array}{l}\text { Vanitha [83], Maurya [84], Kumar et al. [85], } \\
\text { Jain et al. [86], Arivudainambi and Godhandaraman [87] }\end{array}$ \\
\hline & Medhi [88], Madan and Swami [89], Al-Jararha and Madan [90], Madan and \\
Cupplementary variable technique & Choudhury [91], Madan et al. [79], Madan and Choudhury [92], Jianghua and \\
& Jinting [93], Zadeh [94], Wang and Li [95], Ke and Chu. [96], Wang and Li [97], \\
& Ramanath and Kalidass [98], Choudhury and Deka [99] \\
\hline Matrix geometric/matrix method & Alfa [103], Breuer et al. [104], Van Houdt et al. [105], Dudin et al. [106], Luh and Xu \\
& [107], Lee and Luh [108], Ayyappan et al. [109], Jain et al. [110], Yang et al. [111], \\
& Hanbali [112], Jain et al. [113] \\
\hline & Latouche and Ramaswami [114], Baburaj and Manoharan [115], Bocharov et al. \\
Embedded Markov Chain technique & Klimenok [119], Jain and Upadhyaya [120], Jain et al. [121] \\
\hline Maximum entropy analysis & Jain [122], Wang et al. [123, 124], Singh et al. [125] \\
\hline Stochastic decomposition property & Kim and Park [126], Katayama and Kobayashi [127], Dimitriou and Langaris [128], \\
\end{tabular}

The above set of (6) is to be solved under the following boundary conditions at $x=0$. Now

$$
\begin{aligned}
& P_{1, n}(0)=\left(1-r_{1}\right)(1-p) \int_{0}^{\infty} P_{1, n+1}(x) \mu_{1}(x) d x \\
& +(1-p) \int_{0}^{\infty} R_{1, n+1}(x) \mu_{1}(x) d x \\
& +\int_{0}^{\infty} R_{2, n+1}(x) \mu_{2}(x) d x \\
& +\left(1-r_{2}\right) \int_{0}^{\infty} P_{2, n+2}(x) \mu_{2}(x) d x, \quad n \geq 1, \\
& P_{1,0}(0)=\left(1-r_{1}\right)(1-p) \int_{0}^{\infty} P_{1,1}(x) \mu_{1}(x) d x \\
& +(1-p) \int_{0}^{\infty} R_{1,1}(x) \mu_{1}(x) d x \\
& +\int_{0}^{\infty} R_{2,1}(x) \mu_{2}(x) d x \\
& +\left(1-r_{2}\right) \int_{0}^{\infty} P_{2,2}(x) \mu_{2}(x) d x+\lambda Q, \\
& P_{2, n}(0)=\left(1-r_{1}\right) p \int_{0}^{\infty} P_{1, n}(x) \mu_{1}(x) d x \\
& +p \int_{0}^{\infty} R_{1, n}(x) \mu_{1}(x) d x, \quad n \geq 0, \\
& R_{i, n}(0)=r_{i} \int_{0}^{\infty} P_{i, n}(x) \mu_{i}(x) d x, \quad n \geq 0, i=1,2 .
\end{aligned}
$$

Using probability generating function technique, the set of (6)-(7) can be solved to obtain the queue size distribution and the expected number of customers in the system.

3.2. Probability Generating Function (PGF). As the queueing systems have become complex over time, PGF is one of the most powerful tool for providing the solution of set of differential difference equations and tackle with probability problems. With the help of PGF, we can easily convert the discrete sequence of numbers that is, probabilities into a function of dummy variable. Furthermore, PGF is the special case of the $z$-transform. For describing PGF method, we continue the model discussed in Section 3.1. For solving (6)(7), we define the generating functions as follows:

$$
\begin{array}{r}
P_{i}(z, x)=\sum_{n=0}^{\infty} P_{i, n}(x) z^{n} \\
R_{i}(z, x)=\sum_{n=0}^{\infty} R_{i, n}(x) z^{n} \\
|z| \leq 1, \quad i=1,2 .
\end{array}
$$

Multiplying (6)-(7) by appropriate powers of $z$ and then summing over $n$, we have

$$
\begin{array}{ll}
\frac{d}{d x} P_{i}(z, x)+\left(\lambda-\lambda z+\mu_{i}(x)\right) P_{i}(z, x)=0, & i=1,2 \\
\frac{d}{d x} R_{i}(z, x)+\left(\lambda-\lambda z+\mu_{i}(x)\right) R_{i}(z, x)=0, & i=1,2
\end{array}
$$




$$
\begin{aligned}
z P_{1}(z, 0)= & \lambda z Q \\
& +\left(1-r_{1}\right)(1-p) \int_{0}^{\infty} P_{1}(z, x) \mu_{1}(x) d x \\
& +(1-p) \int_{0}^{\infty} R_{1}(z, x) \mu_{1}(x) d x \\
& +\int_{0}^{\infty} R_{2}(z, x) \mu_{2}(x) d x \\
& +\left(1-r_{2}\right) \int_{0}^{\infty} P_{2}(z, x) \mu_{2}(x) d x-\lambda Q, \\
P_{2}(z, 0)= & \left(1-r_{1}\right) p \int_{0}^{\infty} P_{1}(z, x) \mu_{1}(x) d x \\
& +p \int_{0}^{\infty} R_{1}(z, x) \mu_{1}(x) d x, \\
R_{i}(z, 0)= & r_{i} \int_{0}^{\infty} P_{i}(z, x) \mu_{i}(x) d x, \quad i=1,2 .
\end{aligned}
$$

On solving these equations, we obtain the probability generating functions of the number of the customers in the system as follows:

$$
\begin{array}{ll}
P_{i}(z)=P_{i}(z, 0) \frac{\left[1-g_{i}^{*}(\lambda(1-z))\right]}{\lambda(1-z)}, & i=1,2, \\
R_{i}(z)=R_{i}(z, 0) \frac{\left[1-g_{i}^{*}(\lambda(1-z))\right]}{\lambda(1-z)}, & i=1,2,
\end{array}
$$

where $g_{i}^{*}(\lambda(1-z))=\int_{0}^{\infty} e^{-\lambda(1-z)} d g_{i}(x), i=1,2$ is the Laplace-Steiltjes transform of the $i$ th $(i=1,2)$ stage service time.

3.3. Embedded Markov Chain (EMC). A stochastic process is said to be embedded in the continuous time process only when the service of the customer is considered just after the departure or prior the arrival. EMC plays the important role in the performance analysis of continuous Markov chain in which the state parameter is discrete. EMC is an important classical method which is widely used by many researchers for solving the non-Morkovian models. Using EMC technique, we can be easily convert the two dimensional process $[N(t), X(t)]$ into one dimensional process $N(t)$. Further, we can apply this technique for those models where the distributions of interarrival time or service time do not possess the memory less property. Recently, this method was described by Choudhury and Deka [21]. They considered an M/G/1 queueing system with two phases of service wherein the customers arrive according to compound Poisson process with rate $\lambda$.

On finding the server busy at the arrival epoch, all arriving customers join the orbit and try again for receiving service from the server under the linear retrial policy with rate $\nu\left(1-\delta_{n, 0}\right)+n \theta$, where $n$ is the orbit size, $\delta_{i, j}$ represents Kronecker's delta function, $\theta$ is the retrial rate per customer and $v$ can be considered as the rate of the server providing service during the idle state. There is a single server that provides preliminary FES denoted by $B_{1}$ to all arriving customers and provides SOS denoted by $B_{2}$ with probability $p$ to only those customers who opt for it otherwise leaves the system with the complementary probability $\bar{p}=(1-$ $p$ ). During busy states, the server may break down with rate $\alpha_{1}$ during FES and $\alpha_{2}$ during SOS. After repairing, the server renders remaining service and such service times are cumulative and are known as generalized service times having the distribution function $H_{i}(x),(i=1,2)$. The $k$ th $(k \geq 1)$ moments for busy states, repair states and generalized service time are given by $b_{i}^{(k)}, r_{i}^{(k)}, g_{i}^{(k)},(i=1,2)$, receptively. Let $\tau_{n}$ be the time instant at which $n$th service completion occurs. Let us consider the sequence $N_{n}=N\left(\tau_{n}+\right)$ which is embedded Morkov renewal process. Then, we have

$$
\begin{aligned}
& \left(\frac{N_{n}}{N_{n-1}}=j\right) \\
& \quad= \begin{cases}j-1+B_{n} & \text { with probability } \frac{\theta_{j}}{\lambda+\theta_{j}} \\
j+B_{n} & \text { with probability } \frac{\lambda}{\lambda+\theta_{j}},\end{cases}
\end{aligned}
$$

where $B_{n}$ be the number of the customers arriving during the $n$th total service time.

Now, we define $m_{i, j}$ and $m_{j}$ as the probabilities that $j$ customers arrive during $i$ th phase of generalized service time $(\forall i \in 1,2)$ and time interval $\left[B_{1}+B_{2}\right]$ then for $j \in Z^{+}$, we have

$$
\begin{aligned}
m_{i, j} & =\int_{0}^{\infty} \frac{e^{-\lambda x}(\lambda x)^{j} c_{j}^{(n)} d H_{i}(x)}{j !}, \\
m_{j} & =\sum_{i=0}^{j} m_{1, i} m_{2, j-i} .
\end{aligned}
$$

Then, the one step transition matrix is $P=\left(p_{i j}\right)$, where $p_{i j}=$ $\operatorname{Pr}\left(N_{n+1}=j / N_{n}=i\right)$ associated with Morkov chain $\left\{N_{n}\right\}_{n=1}^{\infty}$ is obtained as

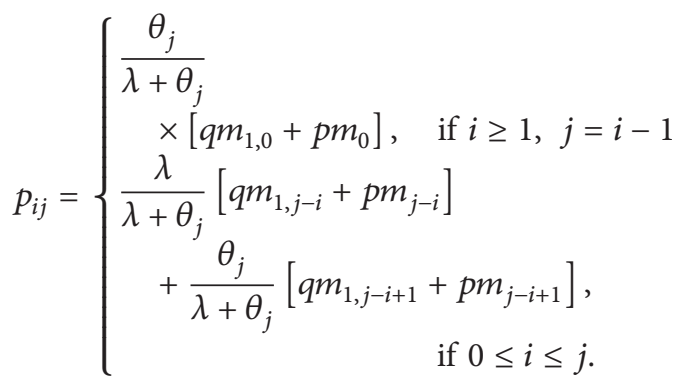

Thus, using $\pi=\pi P$, the Kolmogorov equation associated with Morkov chain is given by

$$
\begin{aligned}
\pi_{j}= & \sum_{i=0}^{j} \frac{\lambda \pi_{i}}{\lambda+\theta_{i}}\left[q m_{1, j-i}+p m_{j-i}\right] \\
& +\sum_{i=1}^{j+1} \frac{\theta_{i} \pi_{i}}{\lambda+\theta_{i}}\left[q m_{1, j-i+1}+p m_{j-i+1}\right], \quad j \geq 0 .
\end{aligned}
$$


Then, the probability generating function technique may be used to solve the above equation.

3.4. Matrix Geometric Method (MGM). Whenever, it is very difficult to obtain neat and closed form analytical solution for queueing problems, then, these congestion situations can be analyzed by applying numerical techniques. MGM is one of the numerical techniques which is suited for this purpose. This approach can be applied whenever the blocks themselves become identical after some initial point. Further, the system can be decomposed into two parts: the initial part and the repetitive part. A significant contribution to this field was made by Neuts [10] for providing the solution of transition probability matrices. Many prominent researches have used this approach in their studies to solve the more complex queueing problems that can be realized in an industrial organization, transportation, and manufacturing environments.

In order to explain MGM, we describe the queue with single working vacation (compare to [22]). Consider M/M/1 queue with arrival rate $\lambda$ and service rate $\mu_{b}$ was considered. Whenever the queue becomes empty, the server begins a working vacation of random length " $V$ " wherein " $V$ " follows an exponential distribution with parameter $\theta$. During a working vacation an arriving customer is served at a rate of $\mu_{v}$. When a vacation ends and there are customers in the queue, the server changes service rate from $\mu_{v}$ to $\mu_{b}$, and a regular busy period starts. Otherwise, the server enters idle period, and a new regular busy period starts when a customer arrival occurs. It is assumed that the interarrival times, service times, and working vacation times are mutually independent. The server provides service in first in first out (FIFO) order.

Let $Q(t)$ be the number of customers in the system at time $t$ and let

$$
\begin{aligned}
& N(t) \\
& = \begin{cases}0, & \text { the server is in working vacation period at time } t \\
1, & \text { the server is in busy period at time } t .\end{cases}
\end{aligned}
$$

Then $\{Q(t), N(t)\}$ is a Markov process with state space $\Omega=$ $\{(n, j) ; n \geq 0, j=0,1\}$, where state $(n, 0), n \geq 1$ denotes that the server is in working vacation state and there are $n$ customers in the system; state $(0,1)$ represents that the server is in idle state; states $(n, 1), n \geq 1$ denote that there are $\mathrm{n}$ customers in the system and the server is in busy state.

Using the lexicographical sequence for the states, the infinitesimal generator can be written as

$$
\widehat{Q}=\left[\begin{array}{cccccc}
A_{0} & C & 0 & 0 & \ldots & \ldots \\
B_{0} & A & C & 0 & \ldots & \ldots \\
0 & B & A & C & \ldots & \ldots \\
0 & 0 & B & A & \ldots & \ldots \\
\ldots & \ldots & \ldots & \ldots & \ldots & \ldots
\end{array}\right]
$$

where

$$
\begin{aligned}
A_{0} & =\left[\begin{array}{cc}
-(\lambda+\theta) & \theta \\
0 & -\lambda
\end{array}\right], \\
C & =\left[\begin{array}{ll}
\lambda & 0 \\
0 & \lambda
\end{array}\right], \\
B_{0} & =\left[\begin{array}{ll}
\mu_{v} & 0 \\
\mu_{b} & 0
\end{array}\right], \\
A & =\left[\begin{array}{cc}
-\left(\lambda+\theta+\mu_{v}\right) & \theta \\
0 & -\left(\lambda+\mu_{b}\right)
\end{array}\right], \\
B & =\left[\begin{array}{cc}
\mu_{v} & 0 \\
0 & \mu_{b}
\end{array}\right] .
\end{aligned}
$$

The structure of $\widehat{Q}$ indicates that $\{Q(t), N(t)\}$ is a quasibirth and death process (see [10]). To analyze this $\mathrm{QBD}$ process, it is necessary to solve for the minimal nonnegative solution of the matrix quadratic equation

$$
R^{2} B+R A+C=0 .
$$

Here, the square matrix $R$ is the rate matrix which can be further used to determine the queue size distribution and other performance measures. Further, with the help of rate matrix $R$, the stationary probability vectors can be easily computed.

3.5. Maximum Entropy Analysis (MEA). MEA is an inherent characteristic of a probabilistic system at equilibrium point. The main objective of the maximum entropy analysis is to provide an approximate approach to estimate an unknown probability distribution. This approach is based on the principle of measure of uncertainty suggested by Shannon [23]. Using this approach, one can obtain the unbiased distribution of the concerned queueing system by maximizing the entropy function defined in terms of known performance indices.

Since 1970's many attempts have been made for applying the method of maximum entropy in the area of queueing theory. Asars and Petersons [24] provided MEA for single server queueing system in which they considered a system that has a countable set $S$ of possible states with probability $\mathbf{p}\left(S_{j}\right)$ of the occurrence of the state $S_{i}$. Thus

$$
\begin{aligned}
\mathbf{p}\left(S_{j}\right) & >0, \\
\sum_{j} \mathbf{p}\left(S_{j}\right) & =1, \quad j=1,2,3, \ldots
\end{aligned}
$$

For estimating the distribution $\mathbf{p}$ based on incomplete information, we assume that the information about $p$ is available in the form of expected values of known function $g_{k} ; k=$ $1,2,3, \ldots, M$ of the states given by

$$
\sum_{S_{n} \in S} g_{k}\left(S_{n}\right) \mathbf{p}\left(S_{n}\right)=G_{k}, \quad 1 \leq k \leq m<\infty .
$$

Here, the number of constraints (19)-(20) is less than the number of possible states which cannot identify the distribution $g$. However, there are a number of distributions that 
satisfy all these constraints. Using the maximum entropy analysis, one may choose the right distribution " $g$." The system entropy is given by

$$
H(g, \mathbf{p})=-\sum_{S_{n} \in S} g\left(S_{i}\right) \log \left[\frac{g\left(S_{i}\right)}{\mathbf{p}\left(S_{i}\right)}\right],
$$

where $\mathbf{p}\left(S_{i}\right)$ are known a priori about the distribution.

Using Lagrange's method of undetermined multipliers, we have

$$
\begin{aligned}
g\left(S_{n}\right) & =Z_{g}^{-1} \mathbf{p}\left(S_{n}\right) \exp \left[-\sum_{k} g_{k}\left(S_{n}\right) \psi_{k}\right], \\
Z_{g} & =\exp \left[\psi_{0}\right] \\
& =\sum_{S_{n} \in S} \mathbf{p}\left(S_{n}\right) \exp \left[-\sum_{k} g_{k}\left(S_{n}\right) \psi_{k}\right],
\end{aligned}
$$

where $\left[\psi_{k}\right]$ are the Lagrangian multipliers corresponding to the set of constraints (19)-(20).

Using this principle, we can suggest a feasible method for approximately analyzing many complex queueing problems. For estimating the probabilistic information measures, maximum entropy analysis is used to obtain queue size distribution of various queueing systems in different frameworks when the moments of higher order attached to the interarrival time, service time and the number of the customers are known. Borzadaran [25] provided a note on maximum entropy for queueing problems. In queueing literature, there are a few papers on phase service queueing models using maximum entropy analysis.

3.6. Stochastic Decomposition Property (SDP). Using this property, we can decompose the random variable of the interest in sum of two or more independent random variables. Stochastic Decomposition Property (SDP) was first established by Fuhrmann and Cooper [26] for M/G/1 type queues in which they decomposed the probability generating function (PGF) of the queue size into two or more independent random variables. We now proceed to provide stochastic decomposition results for $\mathrm{M} / \mathrm{G} / 1$ queueing model with two phases of service discussed in Section 3.3. The existence of stochastic decomposition result can be demonstrated easily by showing

$$
\pi(z)=\Omega(z) \xi(z)
$$

where

$$
\begin{gathered}
\Omega(z) \\
=\frac{\left[(1-\rho)(1-z)\left[q+p b_{2}^{*}\left(A_{2}(z)\right)\right] b_{1}^{*} A_{1}(z)\right]}{\left[\left[q+p b_{2}^{*}\left(A_{2}(z)\right)\right] b_{1}^{*} A_{1}(z)-z\right]}, \\
\xi(z)=\frac{\lambda \psi(z)}{(1-\rho)} .
\end{gathered}
$$

Also $\rho=\rho_{1}\left(1+\alpha_{1} r_{1}^{(1)}\right)+p \rho_{2}\left(1+\alpha_{2} r_{2}^{(1)}\right) ; \rho_{i}=\lambda b_{i}^{(1)}$, for all $i=1,2$.
Here, $\Omega(z)$ is the probability generating function of the system size distribution at departure epoch. Further, $\xi(z)$ is the probability generating function of the conditional distribution of the number of customers present in the orbit.

\section{Performance Measures}

The mathematical analysis of queueing system is done to derive various generic measures using which we can describe the performance of the concerned queueing system. These performance measures are often used by the system designers and analysts for analyzing the real world situations. Performance measures can be further used to give direction to ensure whether the proper level of service is provided by the system facility in terms of response time while avoiding excessive cost. Some queueing performance measures such as queue length, waiting time, idle period, and busy period, are used to analyze in phase service model. For describing these performance measures, we consider the same model which was discussed in the previous Section 2.1. The queue length $\left(L_{q}\right)$, waiting time $\left(W_{q}\right)$, idle period $P(I)$, busy period $P(B)$, respectively, for the model $\mathrm{M} / \mathrm{E}_{k} / 1$ queue are given as follows.

4.1. Queue Length. Queue length can be defined as the number of the customers waiting in the queue for receiving service from the server. While in some situations, the total number of the customers present in the system including those customers who are being served at that moment are referred as "queue length."

Using the generating function method for (2), we can easily obtain the probability generating function which is given by

$$
P(z)=\frac{P_{0}}{1-r z}
$$

where $P_{0}=1-\rho$, and $\rho=\lambda / \mu, r=\lambda / k \mu$.

Using $L_{q}=\left.P^{\prime}(z)\right|_{z=1}$, we have

$$
L_{q}=\frac{(k+1) \lambda \rho}{2 k \mu(1-\rho)} .
$$

Equation (26) provides the result for average queue length.

4.2. Waiting Time. The total time duration spent by a customer in waiting for his turn before service is considered as "waiting time." In wider sense, the total time spent in the system by a customer means the waiting time before service plus service time is called waiting time. It is very important performance characteristic from the customers' point of view. Using Little's formula, we have

$$
W q=\frac{L_{q}}{\lambda}=\frac{(k+1) \rho}{2 k \mu(1-\rho)} .
$$

4.3. Idle and Busy Period. The fraction of time during which the server remains idle (dormant) in the service facility is termed as "idle period." The busy period is initiated when the server provides service for the waiting customers in phases as 
required by the customers that is, a busy period starts with the arrival of a customer at an empty service station and ends only when all waiting customers get their service from the server.

(i) Probability for the busy state is given as

$$
P(B)=\rho .
$$

(ii) Probability for the idle state is given as

$$
P(I)=[1-P(B)]=P_{0} .
$$

4.4. Reliability Indices. Reliability of a system is defined as the probability that the system will perform efficiently throughout the interval $(0, t)$ under operating conditions. Availability is defined as the probability that the system is operating properly when it is requested for use. Reliability and availability are the most desirable properties of most products in the modern world due to their interdisciplinary character.

Let $T$ be the random variable which denotes the failure time of the system. Then, reliability is

$$
R(t)=1-F(t),
$$

where, $F(T)$ is the cumulative distribution function of $T$.

The probability that the system is properly functioning at time $t(\geq 0)$ is defined as the availability of the system. In the case of nonrepairable system, reliability and availability must be identical.

\section{Performance Analysis of Some Queueing Models with Phase Service}

Performance analysis is one of the key issues which should be explored during the design and development of any phase service queueing model. Performance analysis of queueing models with phase service gives an idea to ensure whether the proper level of service is being provided. It is worthwhile to discuss some modelling aspects of queueing characterization. In this section, we describe the performance analysis of some queueing models with phase service. Here, we first discuss some important works related to the phase service queueing models which incorporate other key concepts such as retrial, priority, vacation, unreliable server, optimal control policy, bulk input/service, and discrete time. Furthermore, we review the notable recent works on phase service queueing model.

5.1. Retrial Queueing Model. Retrial queue can be characterized by the fact that whenever arriving customers find the server busy, they are compelled to leave the service area and join some virtual place referred as an "orbit" (see Figure 3). These customers are called "blocked customers" and try their luck again after a random amount of time for service from the orbit. Retrial queueing models are widely used in the stochastic modelling of many real-life congestion situations encountered in computer and telecommunication networks including local and wide area networks with the random multiple access protocols, distribution services, manufacturing plants, and call centers.

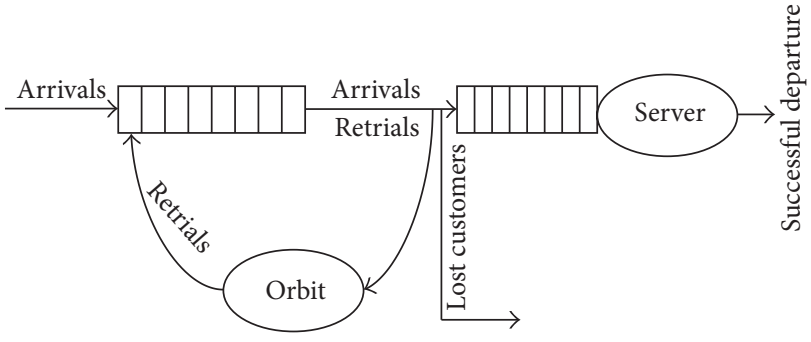

Figure 3: Retrial queueing system.

For early past prominent contributions on retrial queue, we refer the book by Falin and Templeton [27]. Further, the considerable attention has been paid in studying retrial queues with phase service. Artalejo and Choudhury [28] investigated an M/G/1 retrial queue with two-phase service. Choudhury [29] examined the two-phase batch arrival retrial queueing system with Bernoulli vacation. The phase service queueing models with repeated attempts in different frame works by prominent researchers are summarized in Table 2 .

5.2. Priority Queueing Model. Priority queueing models are those in which one or more types of customers have priority over other types of customers. Priority queueing models are an invaluable scheduling method that allows the customers of different classes to receive service in priority to other customers. It is often desirable or even essential to provide different grades of service for different classes of customers. Priority models have two broad categories of priority rules namely, preemptive priority and nonpreemptive priority.

(i) Preemptive Priority Model. In this case, the service of a lower priority customer is interrupted due to arrival of higher priority customer. After the interruption, the customer gets his service again at that point where the service was interrupted however in some other cases he may start the service from some another point or repeat from initial point.

(ii) Non-Preemptive Priority Model. The higher priority customers may not interrupt the service of a lower priority customer; and higher priority customers have to wait till the service of the lower priority customer has been completed.

The schematic diagram of queue with two classes of customers and two-phase service is shown in Figure 4. Some researchers have focused their attention on the priority queueing models with phase type of services which are enumerated as follows. Chakravarthy [30] considered a priority polling system consisting of two queues attended by a single server who served those customers according to the phase type distribution. Krishna Kumar et al. [31] examined an M/G/1 retrial queue with preemptive resume wherein the service of the customers is provided in two phases. Further, Wierman et al. [32] focused their attention on $\mathrm{M} / \mathrm{PH} / \mathrm{k}$ system with two priority classes of customers, high priority and low priority. They demonstrated exactly how many servers are preferable as a function of the load and 
TABLE 2: Literature on retrial queue with phase service.

\begin{tabular}{|c|c|c|c|}
\hline Models & Special features & Authors & Methodology \\
\hline $\mathrm{M} / \mathrm{M} / 1$ & $\begin{array}{l}\text { Vacation interruptions, Erlang- } K \\
\text { type service }\end{array}$ & Ayyappan et al. [132] & Matrix geometric technique \\
\hline $\mathrm{M} / \mathrm{E}_{k} / 1$ & Second optional service & Sekar et al. [133] & Probability generating function \\
\hline \multirow{4}{*}{$\mathrm{M} / \mathrm{G} / 1$} & $\begin{array}{l}\text { Bernoulli vacation, stochastic } \\
\text { decomposition, and two-phase } \\
\text { service }\end{array}$ & Choudhury [134] & $\begin{array}{l}\text { Embedded Markov chain, probability } \\
\text { generating function }\end{array}$ \\
\hline & Server breakdown, SOS & Choudhury and Deka [135] & \multirow{3}{*}{ Probability generating function } \\
\hline & Generalized retrial time, sOS & Choudhury [136] & \\
\hline & $\begin{array}{l}(n-1) \text { types of retrial customers, } \\
n \text {-phases of service }\end{array}$ & Langaris and Dimitriou [137] & \\
\hline $\mathrm{M}^{X} / \mathrm{G} / 1$ & $\begin{array}{l}\text { Bulk arrival, vacation, unreliable } \\
\text { server, and two-phase service }\end{array}$ & Ke and Chang [138] & $\begin{array}{l}\text { Probability generating function, } \\
\text { supplementary variable }\end{array}$ \\
\hline $\mathrm{M}^{X} /\left(\mathrm{G}_{1}, \mathrm{G}_{2}\right) / 1$ & $\begin{array}{l}\text { Bulk arrival, Bernoulli feedback, } K \\
\text { optional vacations, and two phases } \\
\text { of heterogeneous service }\end{array}$ & $\begin{array}{l}\text { Arivudainambi and } \\
\text { Godhandaraman [87] }\end{array}$ & $\begin{array}{l}\text { Probability generating function, } \\
\text { supplementary variable technique }\end{array}$ \\
\hline $\mathrm{BMAP} / \mathrm{PH} / \mathrm{N}$ & $\begin{array}{l}\text { Batch Arrival, server breakdown, } \\
N \text {-policy, and phase type service }\end{array}$ & Kim et al. [139] & Probability generating function \\
\hline
\end{tabular}

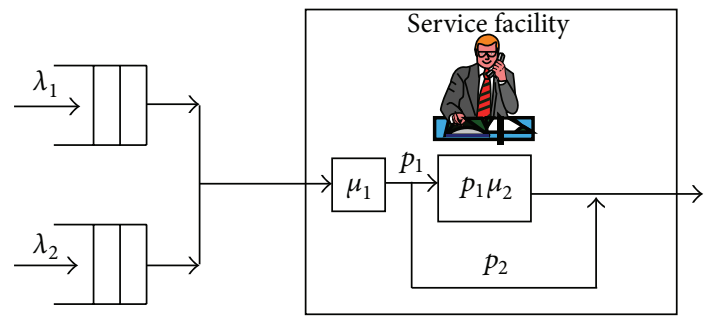

FIgURE 4: Priority queueing system.

service time distribution. Zhao et al. [33] focused on the computation of DBMAP/PH/1 queueing system with priorities. The MAP/PH/1 queue with self-generation of priorities was studied by Krishnamoorthy et al. [34]. Moreover, a priority queue was studied by Sharma and Kumar [35].

5.3. Vacation Queueing Model. Queueing system in which the server is unavailable for a random interval of time is referred as "vacation queueing model." Generally, a vacation period starts whenever the system becomes empty that is, the server is idle. Vacation queueing models are frequently seen in the congestion situations in many areas of industrial problems including computer and communication systems, production and manufacturing systems, transportation and planning. A detailed account on early vacation models can be found in the work of Doshi [36]. Vacation queueing models are further classified into single vacation, multiple vacation and working vacation models, which are explained as given below.

(i) Single Vacation Model (SVM). In such type of vacation model, the server takes a single vacation between two successive busy periods. After returning from vacation, if he finds no customers in the system then he waits in the system for the new arrival.

(ii) Multiple Vacation Model (MVM). After taking the first vacation, the server may take other vacations subsequently till he finds the number of the customers waiting in the system.

(iii) Working Vacation Model (WVM). During the vacation, the server does not stop the service completely but serves the customers with a lower rate or performs some ancillary task. This type of vacation is known as "working vacation." Working vacation queueing model is useful for the system wherein the server may utilize his idle time for different tasks.

Vacation queueing models have been studied by Alfa [37] in different frame works. A two-phase queueing system under Bernoulli vacation schedule has been investigated by Choudhury and Madan [38], Choudhury and Paul [39] in different frameworks. Choudhury et al. [40] examined the steady state behaviour of a batch arrival queue with two phases of heterogeneous service under multiple vacation policy along with Bernoulli vacation schedule. They have obtained the expected number of the customers in the system using the probability generating function technique. Some notable works on vacation queueing models with phase service are reported in Table 3.

5.4. Unreliable Queueing Model. Unreliable server models can be explained as a special case of service interruption models. Unreliable queueing model makes negative impact on the performance of any queueing system. In many practical situations, the server may fail during busy state or idle state and requires repair for restoring the server again. Whenever the breakdown of the server occurs during busy state it is termed as "active break down" while in inactive state that is, idle state it is said to be "passive break down" as shown in Figure 5. In our routine life, we may encounter 
TABLE 3: Literature on vacation queue with phase service.

\begin{tabular}{|c|c|c|c|}
\hline Models & Special features & Authors & Methodology \\
\hline $\mathrm{M} / \mathrm{M} / 1$ & $\begin{array}{l}\text { Second optional service in } \\
\text { batches }\end{array}$ & Jain et al. [86] & Probability generating function \\
\hline \multirow{6}{*}{ M/G/1 } & \multirow{2}{*}{$\begin{array}{l}\text { Retrial queue, Bernoulli } \\
\text { vacation, and two-phase service }\end{array}$} & Choudhury [134] & $\begin{array}{l}\text { Embedded Markov chain, } \\
\text { probability generating function }\end{array}$ \\
\hline & & $\begin{array}{l}\text { Choudhury and Kalita } \\
{[140]}\end{array}$ & \multirow{4}{*}{ Probability generating function } \\
\hline & $\begin{array}{l}\text { Bernoulli vacation, server } \\
\text { breakdown, and two-phase } \\
\text { service }\end{array}$ & Ke and Chang [141] & \\
\hline & Bulk arrival, multiple vacation & $\begin{array}{l}\text { Jeyakumar and } \\
\text { Arumuganathan [142] }\end{array}$ & \\
\hline & $\begin{array}{l}\text { Retrial queue, server breakdown, } \\
\text { batch arrival, and two-phase } \\
\text { service }\end{array}$ & $\begin{array}{l}\text { Kumar and } \\
\text { Arumuganathan [143] }\end{array}$ & \\
\hline & $\begin{array}{l}\text { Multioptional services, } \\
\text { multi-optional vacations, and } \\
\text { unreliable server }\end{array}$ & Jain et al. [72] & $\begin{array}{l}\text { Probability generating function, } \\
\text { supplementary variable } \\
\text { technique }\end{array}$ \\
\hline $\mathrm{M}^{X} /\left(\mathrm{G}_{1}, \mathrm{G}_{2}\right) / 1$ & $\begin{array}{l}\text { Bulk arrival, setup, bilevel } \\
\text { threshold policy, single vacation, } \\
\text { and two phases of essential } \\
\text { service }\end{array}$ & Mary et al. [144] & $\begin{array}{l}\text { Probability generating function, } \\
\text { supplementary variable } \\
\text { technique, and stochastic } \\
\text { decomposition }\end{array}$ \\
\hline BMAP/G/1 & $\begin{array}{l}\text { Bulk arrival, multiple vacations, } \\
\text { and second optional service }\end{array}$ & Wu et al. [145] & Probability generating function \\
\hline
\end{tabular}

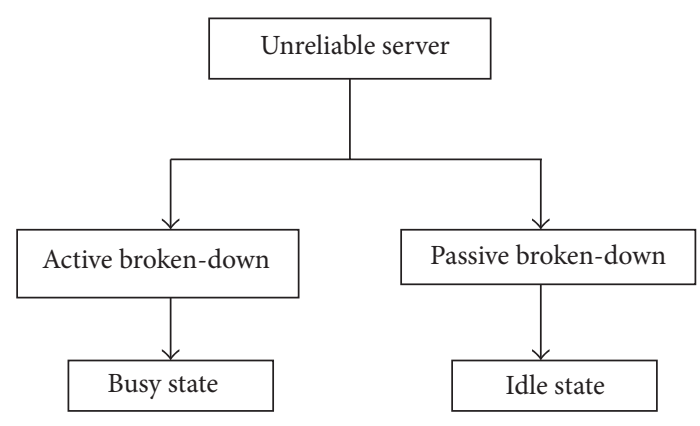

FIGURE 5: Queueing system with unreliable server.

various congestion situations wherein the servers are subject to unpredictable breakdowns. The phase service queueing models with service interruptions have received considerable attention of the researchers working in the area of queueing and reliability theory.

Several authors have studied a variety of models with phase service in different contexts that also include the unpredictable failure of a server and repairs. The repairable queueing system have been studied by Li [41], Li et al. [42], $\mathrm{Li}$ and Cao [43] using phase service in different frame works. Wang [44] analyzed an M/G/1 queue with second optional service and unreliable server. Other related recent works done by researchers in the area of unreliable server queue with phase service are given in Table 4.

5.5. Control Policies for Queueing Models. The optimal control of queueing model is necessary to ensure the smooth functioning of the queueing system from the management view; such models are applicable to many real life situations such as in manufacturing and production control, transportation control, telecommunication process control, and computer science. The optimal control policies may be helpful for controlling the queue levels at different epochs wherein the service should start or stop. There are different policies which have been introduced in the previous studies by many prominent researchers. The concept of the $N$-policy and F-policy was first introduced by Yadin and Naor [45], and Gupta [46], respectively.

A batch arrival queue with an additional phase of service under $\mathrm{N}$-policy was studied, Choudhury and Paul [47]. Further, Pearn and Chang [48] analyzed optimal management of $N$-policy for $\mathrm{M} / \mathrm{E}_{k} / 1$ queueing system with removable server. Choudhury and Madan [49] considered a batch arrival queueing system with modified Bernoulli schedule under $N$ policy. The server remains idle till the queue size becomes $N(\geq 1)$. As the queue size reaches at least $N$, the server instantly starts working and provides two stages of service in succession to each customer. Jain et al. [50] studied the $\mathrm{N}$-policy for two-phase service system with mixed standbys and unreliable server. An $\mathrm{M}^{X} / \mathrm{G} / 1$ queue with an additional phase of second optional service under $\mathrm{N}$-policy consisting of a breakdown period and a delay period was examined by Choudhury et al. [51]. A $\mathrm{M}^{X} / \mathrm{H}_{2} / 1$ queueing system under $\mathrm{N}$-policy with vacation and un-reliable server was investigated by Sharma [9]. Recently, Wu et al. [52] analyzed the MAP/PH/N retrial queue under $N$-policy with finite number of sources wherein arrivals of negative customers operating in a finite state. 
TABLE 4: Literature on unreliable server queue with phase service.

\begin{tabular}{|c|c|c|c|}
\hline Models & Special features & Authors & Methodology \\
\hline $\mathrm{M}^{X} / \mathrm{M} / 1$ & $\begin{array}{l}N \text {-policy, Vacation, startup, bulk } \\
\text { arrival, gated service, and } \\
\text { two-phase service }\end{array}$ & Kumar et al. [85] & \multirow{4}{*}{ Probability generating function } \\
\hline \multirow[t]{3}{*}{$\mathrm{M} / \mathrm{E}_{k} / 1$} & Erlangian phase service & Yu et al. [146] & \\
\hline & $\begin{array}{l}\text { Retrial queue, Bernoulli } \\
\text { vacation, two-phase service }\end{array}$ & Wang and Li [147] & \\
\hline & Second optional service & $\begin{array}{l}\text { Wang and Xu [148], Choudhury } \\
\text { and Tadj [149] }\end{array}$ & \\
\hline \multirow{4}{*}{$\mathrm{M} / \mathrm{G} / 1$} & Startup, second optional service & Wang et al. [150] & \multirow{6}{*}{$\begin{array}{l}\text { Probability generating function, } \\
\text { supplementary variable }\end{array}$} \\
\hline & $\begin{array}{l}\text { Retrial queue, startup, and } \\
\text { two-phase service }\end{array}$ & Dimitriou and Langaris [151] & \\
\hline & $\begin{array}{l}\text { Vacation, two-phase essential } \\
\text { service }\end{array}$ & $\begin{array}{l}\text { Thangaraj and Vanitha [152], Jain } \\
\text { et al. }[130,131]\end{array}$ & \\
\hline & $\begin{array}{l}\text { Two phase service, Bernoulli } \\
\text { vacation }\end{array}$ & Choudhury and Deka [99] & \\
\hline \multirow{2}{*}{$\mathrm{M}^{\mathrm{X}} / \mathrm{G} / 1$} & $\begin{array}{l}\text { Retrial queue, Bulk arrival, Two } \\
\text { phase service }\end{array}$ & $\begin{array}{l}\text { Kumar and Arumuganathan } \\
\text { [143], Choudhury et al. [153] }\end{array}$ & \\
\hline & $\begin{array}{l}\text { Bulk arrival, Bernoulli vacation, } \\
N \text {-policy, and two-phase service }\end{array}$ & Choudhury and Tadj [154] & \\
\hline
\end{tabular}

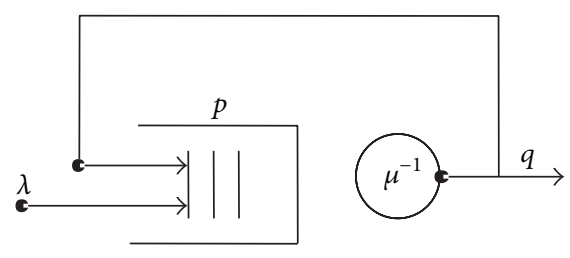

Figure 6: Bernoulli feedback queueing system.

5.6. Feedback Queueing Model. In many congestion situations, if the service of the customer becomes unsuccessful, he is served again and again till his service becomes successful. For this sake, he joins the queue with probability $p$; the customer may leave the system with complementary probability $q(=1-p)$. This phenomenon is known as "Bernoulli feedback" as shown in Figure 6.

During last few years, the literature on Bernoulli feedback queue with phase service has grown up tremendously. Choudhury and Paul [53] dealt with an M/G/1 queue with two phases of heterogeneous services and Bernoulli feedback system, where the server provides first phase of regular service to all the customers. They have derived the queue size distribution at random epoch and at a service completion epoch. Krieger et al. [54] considered a feedback queue with batch Markovian arrivals and phase type services. Moreover, an $\mathrm{M} / \mathrm{G} / 1$ retrial queue with second multioptional service, feedback, and unreliable server was studied by Li and Wang [55]. Kim et al. [56] analyzed the BMAP/G/1 queue with feedback and losses. Zadeh and Shahkar [57] considered an $\mathrm{M} / \mathrm{G} / 1$ queue with two phases of heterogeneous services, Bernoulli feedback and Bernoulli vacation. They have assumed that the customer feedback with probability $p$ to the tail of original queue for repeating of the service until the service is successful; otherwise with probability $1-p=q$ the customer departs from the system forever. Liu et al. [58] worked on an M/G/1 retrial queue with two-phase service and feedback under $N$-policy vacation subject to the server breakdowns and repairs. Salehirad and Badamchizadeh [59] analyzed an M/G/1 queue with $k$ phases of heterogeneous services and random feedback. An M/G/1 feedback queue with two types of service and optional server vacations based on Bernoulli schedule was discussed by Thangaraj and Vanitha [60]. Recently, Kaushik et al. [61] worked on $N$ version system.

5.7. Bulk Queueing Model. In queueing literature when arrivals of the customers/units occur in batches is called "bulk arrival queueing model." On the other hand, queueing situations in which the service of the customers/units is provided in batches by the server is known as "batch service queueing model." In this section, we shall mention some notable investigations which are devoted to bulk queues with the combination of phase service. Yu and Nie [62] studied the MAP/PH/1 queueing system with repairable sever and arrivals in batches. Katayama and Kobayashi [63] considered an $\mathrm{M} / \mathrm{G} / 1$ queueing system wherein a single server provides a batch service in the first phase and an individual service in the second phase. Choudhury and Paul [53] dealt with an $\mathrm{M}^{X} / \mathrm{G} / 1$ queueing system with two phases of heterogeneous service under $N$-policy. They have derived the queue size distribution at random epoch as well as at departure epoch. An M/G/1 queueing system with two-phase batch arrival under Bernoulli schedule has been examined by Choudhury and Madan [38]. J. Kim and B. Kim [64] considered a bulk arrival queue with phase type which required service times in which a single processor serves according to the processorsharing discipline. In Table 5, we refer some important 
TABLE 5: Literature on bulk queues with phase service.

\begin{tabular}{|c|c|c|c|}
\hline Models & Special features & Authors & Methodology \\
\hline \multirow[b]{2}{*}{$\mathrm{M} / \mathrm{M} / 1$} & \multirow{2}{*}{$\begin{array}{l}\text { Bach service, vacation, and additional } \\
\text { phase of optional service }\end{array}$} & Kalyanaraman and Murugan [155] & \multirow{2}{*}{ Probability generating function } \\
\hline & & $\begin{array}{l}\text { Murugan and Kalyanaraman [156], } \\
\text { Sharma [157] }\end{array}$ & \\
\hline \multirow{2}{*}{ M/G/1 } & Quorum, bulk arrival, optional reservice & Tadj and Ke [158] & $\begin{array}{l}\text { Probability generating function, } \\
\text { supplementary variable }\end{array}$ \\
\hline & $\begin{array}{l}\text { Threshold policy, bulk service, and } \\
\text { second optional service }\end{array}$ & Haridass and Arumuganathan [159] & Probability generating function \\
\hline \multirow{3}{*}{$\mathrm{M}^{X} / \mathrm{G} / 1$} & $\begin{array}{l}\text { Bulk arrival, startup, } j \text { additional optional } \\
\text { service }\end{array}$ & $\operatorname{Ke}[160]$ & \multirow{2}{*}{$\begin{array}{l}\text { Probability generating function, } \\
\text { Supplementary variable }\end{array}$} \\
\hline & $\begin{array}{l}\text { server breakdown, retrial, batch arrival, } \\
\text { Bernoulli admission mechanism, and } \\
\text { two-phase of service }\end{array}$ & Choudhury and Deka [161] & \\
\hline & $\begin{array}{l}\text { Retrial queue, bulk arrival, second } \\
\text { optional service, Bernoulli vacation, and } \\
\text { unreliable server }\end{array}$ & Jain et al. [121] & $\begin{array}{l}\text { Probability generating function, } \\
\text { Supplementary variable, } \\
\text { Embedded Markov chain }\end{array}$ \\
\hline $\mathrm{BMAP} / \mathrm{G} / 1$ & Batch arrival, retrial, and phase of service & Kim et al. [162] & \multirow{2}{*}{ Matrix method } \\
\hline \multirow{2}{*}{$\mathrm{MAP} / \mathrm{PH} / 1$} & Batch arrival, $N$-policy, phase service & Kim et al. [163] & \\
\hline & $\begin{array}{l}\text { Batch arrival, batch service, } N \text {-policy, and } \\
\text { phase service }\end{array}$ & Lenin et al. [164] & $\begin{array}{l}\text { Newton approximation } \\
\text { technique }\end{array}$ \\
\hline
\end{tabular}

contributions batch arrival/service queueing model with phase service.

5.8. Discrete Queueing Model. Discrete-time queueing models have received considerable attention of queue theoristsdue to their applications in many real time systems including computer and communication networks, flexible manufacturing system (FMS), broadband integrated services digital network (B-ISDN), and asynchronous transfer mode (ATM). In discrete-time system, the time is treated as a discrete variable (slot), and arrivals and departures can only occur at boundary epochs of time slots. In past literature, the discrete time models are classified into two categories given as below.

(i) Early Arrival Model (EAM). A departure of a customer/unit occurs in precedence over an arrival; that is, the customers/units are assumed to arrive early during a slot.

(ii) Late Arrival Model (LAM). An arrival of a customer/unit occurs in precedence over a departure; that is, the customers/units are assumed to arrive late during a slot.

The merit of the discrete-time queueing model with phase service is continuously recognized by the researchers due to its significant role in performance prediction of various congestion problems. A discrete time queueing model in which jobs require primary and possibly secondary services was analyzed by Alfa and Chakravarthy [65]. Alfa [37] considered a single server discrete queue with vacations and obtained the results for the probability densities of the number of the customers in the system. Li and Yang [66] analyzed discretetime $\mathrm{PH} / \mathrm{Geo} /$ retrial queue. He [67] studied a discrete time $\mathrm{SM} / \mathrm{PH} / 1$ queueing system with multiple types of customers. Further, Atencia et al. $[68,69]$ considered Geo/PH/1 queueing system with repeated attempts. A discrete-time Geo/G/1 retrial queue was considered by Atencia and Moreno [70], Wang and Zhao [71] in which all the arriving customers require a first essential service while only some of them ask for a second optional service. They have obtained the explicit formulae for the stationary distribution and various performance measures. Some significant works on discrete queueing model with phase service are presented in Table 6.

\section{Illustration}

Consider the situation of client server communication (CSC) in which any client makes a request to the packet processing system. The file server serves the client in two phases; in first phase of service, the packet processing system accepts the packet from the client and processes it whereas in the second phase of service it gives the response to the client after processing of the packets. For illustration purpose, we assume that the client makes a request for packet processing wherein the requests arrive in batches of fixed batch size $k=2$ with parameter $\lambda=1$ (arrival rate). The service times of these requests during first phase of service and second phase of service are $\mu_{1}=2$ and $\mu_{2}=3$, respectively. If one of the requests is under process then other requests should be kept in buffer for processing later on with rate $\eta=8$ (retrial rate). The processing of the packet may be interrupted during both phases with rates $\alpha_{1}=0.8, \alpha_{2}=0.9$ (failure rates) and starts processing again with rate $\beta_{1}=1, \beta_{2}=2$ (repair rates), respectively. The client may give feedback again with probability $p=0.3$ in case of unsuccessful service. The server may go for vacations with rate $\omega=0.01$. The expected number of packet processing is calculated using MATLAB software $E\left(L_{S}\right)=53.80$. The expressions available for the expected number of packet which are used for this purpose (compare to [72]). 
TABLE 6: Recent literature on discrete queueing model with phase service.

\begin{tabular}{|c|c|c|c|}
\hline Models & Special features & Authors & Methodology \\
\hline \multirow[t]{2}{*}{$\mathrm{Geo}^{X} / \mathrm{G} / 1$} & $\begin{array}{l}\text { Retrial queue, bulk arrival, starting } \\
\text { failure, stochastic decomposition, } \\
\text { and } l \text {-stage service }\end{array}$ & Jain and Agrawal $[16,17]$ & \multirow[t]{2}{*}{ Probability generating function } \\
\hline & $\begin{array}{l}\text { Retrial queue, feedback, and phase } \\
\text { service }\end{array}$ & Liu and Gao [165] & \\
\hline $\mathrm{Geo} / \mathrm{Geo} / 1$ & Second optional service & Lin et al. [166] & $\begin{array}{l}\text { Matrix analytic approach, } \\
\text { quasi-Newton method }\end{array}$ \\
\hline $\mathrm{MAP} / \mathrm{PH} / 1$ & $\begin{array}{l}\text { Discrete time, multiple working } \\
\text { vacations, and two-phase service }\end{array}$ & Goswami and Selvaraju [167] & Matrix analytic method \\
\hline GI/D-MSP/1 & Discrete time, multiple vacations, & Samanta and Zhang [168] & Matrix geometric method \\
\hline
\end{tabular}

\section{Conclusions}

In this paper, we have reviewed the work done in the area of queueing systems with phase service. The phase service queueing models have found wide applications in the modeling and analysis of day-to-day as well as several industrial systems. The main aim of the present survey is to suggest a unified framework for analyzing the phase service models via queue theoretic approach. The phase service queueing models with the combination of different concepts have been reviewed. Queueing models with phase service are helpful for resolving the problem of congestion and can be treated as an effective tool, for reducing the blocking and delay of the concerned system and are preferred by the system analysts, engineers, and managers for depicting the more realistic scenario of congestion problems. Simulation of the given phenomenon has been done with the help of a real life situation.

\section{Conflict of Interests}

The author declares that there is no conflict of interests regarding the publication of this paper.

\section{References}

[1] I. J. B. F. Adan, W. A. van de Waarsenburg, and J. Wessels, "Analyzing $E_{k} / E_{r} / c$ queues," European Journal of Operational Research, vol. 92, no. 1, pp. 112-124, 1996.

[2] K.-H. Wang, "Optimal control of an $M / E_{k} / 1$ queueing system with removable service station subject to breakdowns," Journal of the Operational Research Society, vol. 48, no. 9, pp. 936-942, 1997.

[3] K.-H. Wang and M.-Y. Kuo, "Profit analysis of the $M / E_{k} / 1$ machine repair problem with a non-reliable service station," Computers \& Industrial Engineering, vol. 32, no. 3, pp. 587-594, 1997.

[4] M. Jain and P. K. Agrawal, "M/ $\mathrm{E}_{\mathrm{k}} / 1$ Queueing system with working vacation," Quality Technology \& Quantitative Management, vol. 4, no. 4, pp. 455-470, 2007.

[5] D. Gross and C. M. Harris, Fundamentals of Queueing Theory, John Wiley \& Sons, New York, NY, USA, 2nd edition, 2000.

[6] K.-H. Wang, K.-W. Chang, and B. D. Sivazlian, "Optimal control of a removable and non-reliable server in an infinite and a finite
$\mathrm{M} / \mathrm{H}_{2} / 1$ queueing system," Applied Mathematical Modelling, vol. 23, no. 8, pp. 651-666, 1999.

[7] K.-H. Wang, H.-T. Kao, and G. Chen, "Optimal management of a removable and non-reliable server in an infinite and a finite $M / H_{k} / 1$ queueing system," Quality Technology \& Quantitative Management, vol. 1, no. 2, pp. 325-339, 2004.

[8] K. H. Wang and K. L. Yen, "ptimal control of an $\mathrm{M} / \mathrm{H}_{k} / 1$ queueing system with a removable server," Mathematical Methods of Operations Research, vol. 57, pp. 255-262, 2003.

[9] R. Sharma, "Threshold N-Policy for $M^{X} / H_{2} / 1$ queueing system with un-reliable server and vacations," Journal of International Academy of Physical Sciences, vol. 14, no. 1, pp. 41-51, 2010.

[10] M. F. Neuts, Matrix Geometric Solutions in Stochastic Models: An Algorithmic Approach, The Johns Hopkins University Press, Baltimore, Md, USA, 1981.

[11] M. F. Neuts, Structured Stochastic Matrices of the M/G/1 Types and Their Applications, vol. 5 of Probability: Pure and Applied, Marcel Dekker, New York, NY, USA, 1989.

[12] M. F. Neuts, Algorithmic Probability, Stochastic Modeling Series, Chapman \& Hall, London, UK, 1995.

[13] S. Asmussen, Applied Probability and Queues, Springer, New York, NY, USA, 2003.

[14] M. S. Kumar and R. Arumuganathan, "On the single server batch arrival retrial queue with general vacation time under Bernoulli schedule and two phases of heterogeneous service," Quality Technology \& Quantitative Management, vol. 5, no. 2, pp. 145-160, 2008.

[15] K. C. Madan, "An $M / G / 1$ queue with second optional service," Queueing Systems: Theory and Applications, vol. 34, no. 1-4, pp. 37-46, 2000.

[16] M. Jain and P. K. Agrawal, "N-policy for the state-dependent batch arrival queueing system with $l$-stage service and modified Bernoulli schedule vacation," Quality Technology \& Quantitative Management, vol. 7, no. 3, pp. 215-230, 2010.

[17] M. Jain and S. Agarwal, "A discrete-time $\mathrm{Geo}^{X} / \mathrm{G} / 1$ retrial queueing system with starting failures and optional service," International Journal of Operational Research, vol. 8, no. 4, pp. 428-457, 2010.

[18] M. Jain and S. Upadhyaya, "Optimal repairable $M^{X} / G / 1$ queue with multi-optional services and Bernoulli vacation," International Journal of Operational Research, vol. 7, no. 1, pp. 109-132, 2010.

[19] D. R. Cox, "The analysis of non-Markovian stochastic processes by the inclusion of supplementary variables," vol. 51, no. 3, pp. 433-441, 1955. 
[20] K. C. Madan and A. Baklizi, "An M/G/1 queue with additional second stage service and optional re-service," International Journal of Information and Management Sciences, vol. 13, no. 4, pp. 13-31, 2002.

[21] G. Choudhury and K. Deka, "A note on M/G/1 queue with two phases of service and linear repeated attempts subject to random breakdown," International Journal of Information and Management Sciences, vol. 20, no. 4, pp. 547-563, 2009.

[22] N. Tian, X. Zhao, and K. Wang, "The $M / M / 1$ queue with single working vacation," International Journal of Information and Management Sciences, vol. 19, no. 4, pp. 621-634, 2008.

[23] C. E. Shannon, "A mathematical theory of communication," Bell System Technical Journal, vol. 27, pp. 379-423, 1948.

[24] A. Asars and E. Petersons, "A maximum entropy analysis of single server queueing system with self-similar input process, scientific proceedings of RTU," Series 7, Telecommunications and Electronics, 2002.

[25] G. R. M. Borzadaran, "A note on maximum entropy in queueing problems," Economic Quality Control, vol. 24, no. 2, pp. 263-267, 2009.

[26] S. W. Fuhrmann and R. B. Cooper, "Stochastic decompositions in the $M / G / 1$ queue with generalized vacations," Operations Research, vol. 33, no. 5, pp. 1117-1129, 1985.

[27] G. I. Falin and J. G. C. Templeton, Retrial Queues, Chapman and Hall, London, UK, 1997.

[28] J. R. Artalejo and G. Choudhury, "Steady state analysis of an $M / G / 1$ queue with repeated attempts and two-phase service," Quality Technology \& Quantitative Management, vol. 1, no. 2, pp. 189-199, 2004.

[29] G. Choudhury, "A two phase batch arrival retrial queueing system with Bernoulli vacation schedule," Applied Mathematics and Computation, vol. 188, no. 2, pp. 1455-1466, 2007.

[30] S. R. Chakravarthy, "Analysis of a priority polling system with group services," Communications in Statistics, vol. 14, no. 1-2, pp. 25-49, 1998.

[31] B. Krishna Kumar, A. Vijayakumar, and D. Arivudainambi, "An M/G/1 retrial queueing system with two-phase service and preemptive resume," Annals of Operations Research, vol. 113, pp. 61-79, 2002.

[32] A. Wierman, T. Osogami, M. Harchol-Balter, and A. SchellerWolf, "How many servers are best in a dual-priority $\mathrm{M} / \mathrm{PH} / k$ system?” Performance Evaluation, vol. 63, no. 12, pp. 1253-1272, 2006.

[33] J. A. Zhao, B. Li, X. R. Cao, and I. Ahmad, "A matrix-analytic solution for the DB MAP/PH/1 priority queue," Queueing System, vol. 53, pp. 127-145, 2006.

[34] A. Krishnamoorthy, S. Babu, and V. C. Narayanan, "The $\mathrm{MAP} /(\mathrm{PH} / \mathrm{PH}) / 1$ queue with self-generation of priorities and non-preemptive service," European Journal of Operational Research, vol. 195, no. 1, pp. 174-185, 2009.

[35] R. Sharma and G. Kumar, "Unreliable server M/M/1 queue with priority queueing system," International Journal of Engineering and Technical Research, pp. 368-371, 2014.

[36] B. T. Doshi, "Queueing systems with vacations-a survey," Queueing Systems: Theory and Applications, vol. 1, no. 1, pp. 29$66,1986$.

[37] A. S. Alfa, "A discrete queue MAP/PH/1 queue with vacations and exhaustive time-limited service," Operations Research Letters, vol. 18, no. 1, pp. 31-40, 1995.
[38] G. Choudhury and K. C. Madan, "A two phase batch arrival queueing system with a vacation time under Bernoulli schedule," Applied Mathematics and Computation, vol. 149, no. 2, pp. 337-349, 2004.

[39] G. Choudhury and M. Paul, "A two phases queueing system with Bernoulli vacation schedule under multiple vacation policy," Statistical Methodology, vol. 3, no. 2, pp. 174-185, 2006.

[40] G. Choudhury, L. Tadj, and M. Paul, "Steady state analysis of an $M^{x} / G / 1$ queue with two phase service and Bernoulli vacation schedule under multiple vacation policy," Applied Mathematical Modelling, vol. 31, no. 6, pp. 1079-1091, 2007.

[41] Q. L. Li, "Queueing system $\mathrm{PH} / \mathrm{PH}(\mathrm{PH} / \mathrm{PH}) / 1$ with the repairable server," Mathematical Statistics and Applied Probability, vol. 10, pp. 75-83, 1995.

[42] Q. L. Li, Y. Tan, and Y. Sun, “The SM/PH/1 queue with repairable server of PH lifetime," in Proceedings of the 14th IFAC Triennial World Congress, vol. A, pp. 297-305, Beijing, China, 1999.

[43] Q. L. Li and J. Cao, "The repairable queue MAP/PH(M/PH)/2 with interdependent repairs," Journal of Systems Science and Complexity, vol. 20, no. 1, pp. 78-86, 2000.

[44] J. Wang, "An $M / G / 1$ queue with second optional service and server breakdowns," Computers \& Mathematics with Applications, vol. 47, no. 10-11, pp. 1713-1723, 2004.

[45] M. Yadin and P. Naor, "Queueing system with a removable service station," Operational Research Quarterly, vol.14, pp. 393405, 1963.

[46] S. M. Gupta, "Interrelationship between controlling arrival and service in queueing systems," Computers and Operations Research, vol. 22, no. 10, pp. 1005-1014, 1995.

[47] G. Choudhury and M. Paul, "A batch arrival queue with a second optional service channel under N-policy," Stochastic Analysis and Applications, vol. 24, no. 1, pp. 1-21, 2006.

[48] W. L. Pearn and Y. C. Chang, "Optimal management of the Npolicy $\mathrm{M} / \mathrm{E}_{k} / 1$ queuing system with a removable service station: a sensitivity investigation," Computers and Operations Research, vol. 31, no. 7, pp. 1001-1015, 2004.

[49] G. Choudhury and K. C. Madan, "A two-stage batch arrival queueing system with a modified Bernoulli schedule vacation under N-policy," Mathematical and Computer Modelling, vol. 42, no. 1-2, pp. 71-85, 2005.

[50] M. Jain, G. C. Sharma, and S. Chakrawarti, "N-policy of a two-phase service system with mixed standbys under unreliable server," Jñānābha, vol. 36, pp. 169-182, 2006.

[51] G. Choudhury, J.-C. Ke, and L. Tadj, “The N-policy for an unreliable server with delaying repair and two phases of service," Journal of Computational and Applied Mathematics, vol. 231, no. 1, pp. 349-364, 2009.

[52] J. Wu, Z. Liu, and G. Yang, "Analysis of the finite source $\mathrm{MAP} / \mathrm{PH} / \mathrm{N}$ retrial G-queue operating in a random environment," Applied Mathematical Modelling, vol. 35, no. 3, pp. 11841193, 2011.

[53] G. Choudhury and M. Paul, "A two phase queueing system with Bernoulli feedback," International Journal of Information and Management Sciences, vol. 16, no. 1, pp. 35-52, 2005.

[54] U. Krieger, V. I. Klimenok, A. V. Kazimirsky, L. Breuer, and A. N. Dudin, "A BMAP $|P H| 1$ queue with feedback operating in a random environment," Mathematical and Computer Modelling, vol. 41, no. 8-9, pp. 867-882, 2005.

[55] J. Li and J. Wang, "An $M / G / 1$ retrial queue with second multi-optional service, feedback and unreliable server," Applied Mathematics-A Journal of Chinese Universities, vol. 21, no. 3, pp. 252-262, 2006. 
[56] C. S. Kim, V. Klimenok, G. Tsarenkov, L. Breuer, and A. Dudin, "The BMAP/G/1/PH/1/M tandem queue with feedback and losses," Performance Evaluation, vol. 64, pp. 802-818, 2007.

[57] A. B. Zadeh and G. H. Shahkar, "A two phases queue system with Bernoulli feedback and Bernoulli schedule server vacation," International Journal of Information and Management Sciences, vol. 19, no. 2, pp. 329-338, 2008.

[58] Z. Liu, J. Wu, and G. Yang, "An M/G/1 retrial G-queue with preemptive resume and feedback under $N$-policy subject to the server breakdowns and repairs," Computers \& Mathematics with Applications, vol. 58, no. 9, pp. 1792-1807, 2009.

[59] M. R. Salehirad and A. Badamchizadeh, "On the multi-phase $M / G / 1$ queueing system with random feedback," Central European Journal of Operations Research, vol. 17, no. 2, pp. 131-139, 2009.

[60] V. Thangaraj and S. Vanitha, "A single server M/G/1 feedback queue with two types of service having general distribution," International Mathematical Forum, vol. 5, no. 1, pp. 15-33, 2010.

[61] G. Kumar, M. Kaushik, R. Sharma, and Preeti, "Availability analysis for embedded system with N-version programming using fuzzy approach," International Journal of Software Engineering, Technology and Applications. In press.

[62] H. B. Yu and Z. K. Nie, "The MAP/PH(PH/PH)/1 discretetime queueing system with repairable server," Chinese Quarterly Journal of Mathematics, vol. 16, no. 2, pp. 60-63, 2001.

[63] T. Katayama and K. Kobayashi, "Sojourn time analysis of a twophase queueing system with exhaustive batch-service and its vacation model," Mathematical and Computer Modelling, vol. 38, no. 11-13, pp. 1283-1291, 2003.

[64] J. Kim and B. Kim, "The processor-sharing queue with bulk arrivals and phase-type services," Performance Evaluation, vol. 64, no. 4, pp. 277-297, 2007.

[65] A. S. Alfa and S. Chakravarthy, "A discrete queue with the Markovian arrival process and phase type primary and secondary services," Communications in Statistics. Stochastic Models, vol. 10, no. 2, pp. 437-451, 1994.

[66] H. Li and T. Yang, "Steady-state queue size distribution of discrete-time $\mathrm{PH} / \mathrm{Geo} / 1$ retrial queues," Mathematical and Computer Modelling, vol. 30, no. 3-4, pp. 51-63, 1999.

[67] Q. M. He, "Age process, workload process, sojourn times, and waiting times in a discrete time $\mathrm{SM}[\mathrm{K}] / \mathrm{PH}[\mathrm{K}] / 1 / \mathrm{FCFS}$ queue," Queueing Systems. Theory and Applications, vol. 49, no. 3-4, pp. 363-403, 2005.

[68] I. Atencia, P. Moreno, and G. Bouza, "An $\mathrm{M}_{2} / \mathrm{G}_{2} / 1$ retrial queue with priority customers, 2nd optional service and linear retrial policy," Revista Investigacion Operacional, vol. 27, no. 3, pp. 229248, 2006.

[69] I. Atencia, P. P. Bocharov, and P. Moreno, "A discrete-time $\mathrm{Geo} / \mathrm{PH} / 1$ queueing system with repeated attempts," Mathematical Models, Computational Methods, vol. 6, no. 3, pp. 272-280, 2006.

[70] I. Atencia and P. Moreno, "Geo/G/1 retrial queue with 2nd optional service," International Journal of Operational Research, vol. 1, no. 4, pp. 340-362, 2006.

[71] J. Wang and Q. Zhao, "A discrete-time Geo/G/1 retrial queue with starting failures and second optional service," Computers \& Mathematics with Applications, vol. 53, pp. 115-127, 2007.

[72] M. Jain, G. C. Sharma, and R. Sharma, "Unreliable $M^{X} /$ $\left(G_{1}, G_{2}\right) / 1$ retrial queue with bernoulli feedback under modified vacation policy," International Journal of Information and Management Sciences. In press.
[73] R. K. Rana, "Queueing problems with arrivals in general stresm and phase type service," Metrika, vol. 18, no. 1, pp. 69-80, 1972.

[74] J. R. Murray and J. R. Kelton, “The transient behavior of $M / E_{k} / 2$ queue and steady-state simulation," Computers \& Operations Research, vol. 15, no. 4, pp. 357-367, 1988.

[75] D. D. Selvam and V. Sivasankaran, "A two-phase queueing system with server vacations," Operations Research Letters, vol. 15, no. 3, pp. 163-169, 1994.

[76] K. C. Madan, "An M/G/1 queueing system with additional optional service and no waiting capacity," Microelectronics Reliability, vol. 34, no. 3, pp. 521-527, 1994.

[77] K. C. Madan, "On a single server queue with two-stage heterogeneous service and deterministic server vacations," International Journal of Systems Science, vol. 32, no. 7, pp. 837-844, 2001.

[78] D. I. Choi and T.-S. Kim, "Analysis of a two-phase queueing system with vacations and Bernoulli feedback," Stochastic Analysis and Applications, vol. 21, no. 5, pp. 1009-1019, 2003.

[79] K. C. Madan, Z. R. Al-Rawi, and A. D. Al-Nasser, "On $\mathrm{Mx} /(\mathrm{G} 1 \mathrm{G} 2) / 1 / \mathrm{G}(\mathrm{BS}) / \mathrm{Vs}$ vacation queue with two types of general heterogeneous service," Journal of Applied Mathematics and Decision Sciences, vol. 2005, no. 3, pp. 123-135, 2005.

[80] J. D. Griffiths, G. M. Leonenko, and J. E. Williams, "The transient solution to $M / E_{k} / 1$ queue," Operations Research Letters, vol. 34, no. 3, pp. 349-354, 2006.

[81] J.-C. Ke and Y.-K. Chu, "Optimization on bicriterion policies for M/G/1 system with second optional service," Journal of Zhejiang University: Science A, vol. 9, no. 10, pp. 1437-1445, 2008.

[82] M. S. Kumar and R. Arumuganathan, "Performance analysis of an $M / G / 1$ retrial queue with non-persistent calls, two phases of heterogeneous service and different vacation policies," International Journal of Open Problems in Computer Science and Mathematics, vol. 2, no. 2, pp. 196-214, 2009.

[83] V. Thangaraj and S. Vanitha, "A two phase $M / G / 1$ feedback queue with multiple server vacation," Stochastic Analysis and Applications, vol. 27, no. 6, pp. 1231-1245, 2009.

[84] V. N. Maurya, "On optimality aspects of a generalized $\mathrm{M}^{\mathrm{x}} / \mathrm{E}_{\mathrm{k}} / 1 / \infty$ queueing model-transient approach," International Journal of Engineering Research and Applications, vol. 2, no. 4, pp. 355-368, 2009.

[85] V. V. Kumar, B. V. H. Prasad, and K. Chandan, “Optimal strategy analysis of an $N$-policy two phase $M^{x} / M / 1$ gated queueing system with server startup and breakdowns," International Journal of Open Problems in Computer Science and Mathematics, vol. 3, no. 4, pp. 563-584, 2010.

[86] M. Jain, G. C. Sharma, and R. Sharma, "Maximum entropy approach for un-reliable server vacation queueing model with optional bulk service," Journal of King Abduaziz University: Engineering Sciences, vol. 23, no. 2, pp. 89-11, 2011.

[87] D. Arivudainambi and P. Godhandaraman, "A batch arrival retrial queue with two phases of service, feedback and $K$ optional vacations," Applied Mathematical Sciences, vol. 6, no. 21-24, pp. 1071-1087, 2012.

[88] J. Medhi, "A single server Poisson input queue with a second optional channel," Queueing Systems, vol. 42, no. 3, pp. 239-242, 2002.

[89] K. C. Madan and H. M. Swami, "Steady state analysis of an $\mathrm{M} / \mathrm{D} / 1$ queue with two stages of heterogeneous server vacations $\left(\mathrm{M} / \mathrm{D} / \mathrm{G}_{1}, \mathrm{G}_{2} / 1\right.$ /queue)," Revista Investigacion Operacional, vol. 23, no. 2, pp. 150-163, 2002. 
[90] J. Al-Jararha and K. C. Madan, "An $M / G / 1$ queue with second optional service with general service time distribution," International Journal of Information and Management Sciences, vol. 14, no. 2, pp. 47-56, 2003.

[91] K. C. Madan and G. Choudhury, "A single server queue with two phases of heterogeneous service under Bernoulli schedule and a general vacation time," International Journal of Information and Management Sciences, vol. 16, no. 2, pp. 1-16, 2005.

[92] K. C. Madan and G. Choudhury, "Steady state analysis of an $M^{X} /\left(G_{1}, G_{2}\right) / 1$ queue with restricted admissibility and random setup time," International Journal of Information and Management Sciences, vol. 17, no. 2, pp. 33-56, 2006.

[93] L. Jianghua and W. Jinting, "An $M / G / 1$ retrial queue with second multi-optional service, feedback and unreliable server," Applied Mathematics B, vol. 21, no. 3, pp. 252-262, 2006.

[94] A. B. Zadeh, "An $\mathrm{M}^{\mathrm{x}} /\left(\mathrm{G}_{1}, \mathrm{G}_{2}\right) / 1 / \mathrm{G}(\mathrm{BS}) / \mathrm{V}_{\mathrm{s}}$ with optional second service and admissibility restricted," International Journal of Information Management, vol. 20, pp. 305-316, 2009.

[95] J. Wang and J. Li, "A single server retrial queue with general retrial times and two-phase service," Journal of Systems Science and Complexity, vol. 22, no. 2, pp. 291-302, 2009.

[96] J.-C. Ke and Y.-K. Chu, "Notes of M/G/1 system under the $<p, T>$ policy with second optional service," Central European Journal of Operations Research, vol. 17, no. 4, pp. 425-431, 2009.

[97] J. Wang and J. Li, "Analysis of the $M^{[X]} / \mathrm{G} / 1$ queue with second multi-optional service and unreliable server," Acta Mathematicae Applicatae Sinica, vol. 26, no. 3, pp. 353-368, 2010.

[98] K. Ramanath and K. Kalidass, "A two phase service $M / G / 1$ vacation queue with general retrial times and non-persistent customers," International Journal of Open Problems in Computer Science and Mathematics, vol. 3, no. 2, pp. 175-185, 2010.

[99] G. Choudhury and M. Deka, "A single server queueing system with two phases of service subject to server breakdown and Bernoulli vacation," Applied Mathematical Modelling, vol. 36, no. 12, pp. 6050-6060, 2012.

[100] V. Ramaswami and D. M. Lucantoni, "Algorithms for the multiserver queue with phase type service," Communications in Statistics. Stochastic Models, vol. 1, no. 3, pp. 393-417, 1985.

[101] J. Y. Le Boudec, "Steady-state probabilities of the $\mathrm{PH} / \mathrm{PH} / 1$ queue," Queueing Systems. Theory and Applications, vol. 3, no. 1, pp. 73-87, 1988.

[102] J. E. Diamond and A. S. Alfa, "Matrix analytical method for $\mathrm{M} / \mathrm{PH} / 1$ retrial queues," Communications in Statistics. Stochastic Models, vol. 11, no. 3, pp. 447-470, 1995.

[103] Q.-M. He and A. S. Alfa, "Computational analysis of $M M A P[K] / P H[K] / 1$ queues with a mixed FCFS and LCFS service discipline," Naval Research Logistics, vol. 47, no. 5, pp. 399-421, 2000.

[104] L. Breuer, A. Dudin, and V. Klimenok, "A retrial BMAP/PH/N system," Queueing Systems: Theory and Applications, vol. 40, no. 4, pp. 433-457, 2002.

[105] B. Van Houdt, R. B. Lenin, and C. Blondia, "Delay distribution of (Im)patient customers in a discrete time $D-M A P / P H / 1$ queue with age-dependent service times," Queueing Systems: Theory and Applications, vol. 45, no. 1, pp. 59-73, 2003.

[106] A. N. Dudin, A. V. Kazimirsky, and V. I. Klimenok, "The queueing model $\mathrm{MAP} / \mathrm{PH} / \mathrm{1} / \mathrm{N}$ with feedback operating in a Markovian random environment," The Australian Journal of Statistics, vol. 34, no. 2, pp. 101-110, 2005.

[107] H. Luh and Z. Z. Xu, "PH/PH/1 queueing models in mathematica for performance evaluation," International Journal of Operational Research, vol. 2, no. 2, pp. 81-88, 2005.
[108] Y.-H. Lee and H. Luh, "Characterizing output processes of $\mathrm{E}_{m} / \mathrm{E}_{k} / 1$ queues," Mathematical and Computer Modelling, vol. 44, no. 9-10, pp. 771-789, 2006.

[109] G. Ayyappan, G. Sekar, and A. M. G. Subramanian, "M/M/1 retrial queueing system with two types of vacation policies under Erlang-K type service," International Journal of Computer Applications, vol. 2, no. 8, pp. 9-18, 2010.

[110] M. Jain, G. C. Sharma, and R. Sharma, "Matrix-geometric method for working vacation queueing system with second optional service and vacation interruptions," Mathematics Today, vol. 26, pp. 14-27, 2010.

[111] D.-Y. Yang, K.-H. Wang, and Y.-T. Kuo, "Economic application in a finite capacity multi-channel queue with second optional channel," Applied Mathematics and Computation, vol. 217, no. 18, pp. 7412-7419, 2011.

[112] A. A. Hanbali, "Busy period analysis of the level dependent $\mathrm{PH} / \mathrm{PH} / 1 / \mathrm{K}$ queue," Queueing Systems, vol. 67, no. 3, pp. 221249, 2011.

[113] M. Jain, G. C. Sharma, and R. Sharma, "Optimal control of $(\mathrm{N}, \mathrm{F})$ policy for unreliable server queue with multi-optional phase repair and start-up," International Journal of Mathematics in Operational Research, vol. 4, no. 2, pp. 152-174, 2012.

[114] G. Latouche and V. Ramaswami, "The PH/PH/1 queue at epochs of queue size change," Queueing Systems. Theory and Applications, vol. 25, no. 1-4, pp. 97-114, 1997.

[115] C. Baburaj and M. Manoharan, "A finite capacity M/G/1 queue with single and batch services," International Journal of Information and Management Sciences, vol. 15, no. 3, pp. 89-96, 2004.

[116] P. P. Bocharov, R. Manzo, and A. V. Pechinkin, "Analysis of a two-phase queueing system with a Markov arrival process and losses," Journal of Mathematical Sciences, vol. 131, no. 3, pp. 5606-5613, 2005.

[117] P. P. Bocharov, R. Manzo, and A. V. Pechinkin, "Two-phase queueing system with a Markov arrival process and blocking," Journal of Mathematical Sciences (New York), vol. 132, no. 5, pp. 578-589, 2006.

[118] A. Al-khedhairi and L. Tadj, "A bulk service queue with a choice of service and re-service under Bernoulli schedule," International Journal of Contemporary Mathematical Sciences, vol. 2, no. 23, pp. 1107-1120, 2007.

[119] O. S. Taramin and V. I. Klimenok, "Two-phase queuing system with a threshold strategy of retrial calls," Automatic Control and Computer Sciences, vol. 43, no. 6, pp. 285-294, 2009.

[120] M. Jain and S. Upadhyaya, "A quorum queueing system with multiple choices of service and optional re-service under $\mathrm{N}$ policy and admission control," Mathematics Today, vol. 26, pp. 53-67, 2010.

[121] M. Jain, G. C. Sharma, and R. Sharma, "A batch arrival retrial queuing system for essential and optional services with server breakdown and Bernoulli vacation," International Journal of Internet and Enterprise Management, vol. 8, no. 1, pp. 16-45, 2012.

[122] M. Jain, "A maximum entropy analysis for $M^{X} / G / 1$ queueing system at equilibrium," Journal of King Abduaziz University, vol. 10, no. 1, pp. 57-65, 1998.

[123] K.-H. Wang, S.-L. Chuang, and W.-L. Pearn, "Maximum entropy analysis to the $\mathrm{N}$ policy M/G/1 queueing system with a removable server," Applied Mathematical Modelling, vol. 26, no. 12, pp. 1151-1162, 2002. 
[124] K.-H. Wang, L.-P. Wang, J.-C. Ke, and G. Chen, "Comparative analysis for the $\mathrm{N}$ policy $\mathrm{M} / \mathrm{G} / 1$ queueing system with a removable and unreliable server," Mathematical Methods of Operations Research, vol. 61, no. 3, pp. 505-520, 2005.

[125] C. J. Singh, M. Jain, and B. Kumar, "Queueing model with state-dependent bulk arrival and second optional service," International Journal of Mathematics in Operational Research, vol. 3, no. 3, pp. 322-340, 2011.

[126] T.-S. Kim and H.-M. Park, "Cycle analysis of a two-phase queueing model with threshold," European Journal of Operational Research, vol. 144, no. 1, pp. 157-165, 2003.

[127] T. Katayama and K. Kobayashi, "Sojourn time analysis of a queueing system with two-phase service and server vacations," Naval Research Logistics, vol. 54, no. 1, pp. 59-65, 2007.

[128] I. Dimitriou and C. Langaris, "Analysis of a retrial queue with two-phase service and server vacations," Queueing Systems: Theory and Applications, vol. 60, no. 1-2, pp. 111-129, 2008.

[129] H.-M. Park, T.-S. Kim, and K. C. Chae, "Analysis of a twophase queueing system with a fixed-size batch policy," European Journal of Operational Research, vol. 206, no. 1, pp. 118-122, 2010.

[130] M. Jain, G. C. Sharma, and R. Sharma, "Unreliable server $M / G / 1$ queue with multi-optional services and multi-optional vacations," International Journal of Mathematics in Operational Research, vol. 5, no. 2, pp. 145-169, 2013.

[131] M. Jain, R. Sharma, and G. C. Sharma, "Multiple vacation policy for $\mathrm{M}^{\mathrm{X}} / \mathrm{H}_{\mathrm{k}} / 1$ queue with un-reliable server," Journal of Industrial Engineering International: A Springer Open Journal, vol. 9, no. 36, pp. 1-11, 2013.

[132] G. Ayyappan, G. Sekar, and A. M. G. Subramanian, "M/M/1 retrial queueing system with vacation interruptions under Erlang-K service," International Journal of Computer Applications, vol. 2, no. 2, pp. 52-57, 2010.

[133] G. Sekar, G. Ayyappan, and M. G. Subramanian, "ingle server retrial queues with second optional service under Erlang services," International Journal of Mathematical Archive, vol. 2, no. $1,2011$.

[134] G. Choudhury, "Steady state analysis of an M/G/1 queue with linear retrial policy and two phase service under Bernoulli vacation schedule," Applied Mathematical Modelling, vol. 32, no. 12, pp. 2480-2489, 2008.

[135] G. Choudhury and K. Deka, "An $M / G / 1$ retrial queueing system with two phases of service subject to the server breakdown and repair," Performance Evaluation, vol. 65, no. 10, pp. 714-724, 2008.

[136] G. Choudhury, "An M/G/1 retrial queue with an additional phase of second service and general retrial times," International Journal of Information and Management Sciences, vol. 20, pp. 114, 2009.

[137] C. Langaris and I. Dimitriou, "A queueing system with \$n\$phases of service and \$(n-1)\$-types of retrial customers," European Journal of Operational Research, vol. 205, no. 3, pp. 638649, 2010.

[138] J.-C. Ke and F.-M. Chang, " $\mathrm{M}^{[x]} /\left(\mathrm{G}_{1}, \mathrm{G}_{2}\right) / 1$ retrial queue under Bernoulli vacation schedules with general repeated attempts and starting failures," Applied Mathematical Modelling, vol. 33, no. 7, pp. 3186-3196, 2009.

[139] C. Kim, V. I. Klimenok, and D. S. Orlovsky, "The BMAP/PH/N retrial queue with Markovian flow of breakdowns," European Journal of Operational Research, vol. 189, no. 3, pp. 1057-1072, 2008.
[140] G. Choudhury and S. Kalita, "A two-phase queueing system with repeated attempts and Bernoulli vacation schedule," International Journal of Operational Research, vol. 5, no. 4, pp. 392407, 2009.

[141] J.-C. Ke and F.-M. Chang, "Analysis of a batch retrial queue with Bernoulli vacation and starting failures," International Journal of Services Operations and Informatics, vol. 5, no. 2, pp. 95-114, 2010.

[142] S. Jeyakumar and R. Arumuganathan, "Steady state analysis of a $\mathrm{M}^{x} / \mathrm{G} / 1$ queue with two service modes and multiple vacations," International Journal of Industrial and Systems Engineering, vol. 3, no. 6, pp. 692-710, 2008.

[143] M. S. Kumar and R. Arumuganathan, "An $\mathrm{M}^{X} / \mathrm{G} / 1$ retrial queue with two-phase service subject to active server breakdowns and two types of repair," International Journal of Operational Research, vol. 8, no. 3, pp. 261-291, 2010.

[144] K. J. Mary, M. I. Begum, and M. J. Parveen, "Bi-level threshold policy of $M^{x} /\left(G_{1}, G_{2}\right) / 1$ queue with early setup and single vacation," International Journal of Operational Research, vol. 10, no. 4, pp. 469-493, 2011.

[145] J. Wu, Z. Liu, and Y. Peng, "On the BMAP/G/1 G-queues with second optional service and multiple vacations," Applied Mathematical Modelling, vol. 33, no. 12, pp. 4314-4325, 2009.

[146] M. Yu, Y. Tang, Y. Fu, and L. Pan, "An $M / E_{k} / 1$ queueing system with no damage service interruptions," Mathematical and Computer Modelling, vol. 54, no. 5-6, pp. 1262-1272, 2011.

[147] J. Wang and J. Li, "A repairable $M / G / 1$ retrial queue with Bernoulli vacation and two-phase service," Quality Technology \& Quantitative Management, vol. 5, no. 2, pp. 179-192, 2008.

[148] W. L. Wang and G. Q. Xu, "The well-posedness of an $M / G / 1$ queue with second optional service and server breakdown," Computers \& Mathematics with Applications, vol. 57, no. 5, pp. 729-739, 2009.

[149] G. Choudhury and L. Tadj, "An $M / G / 1$ queue with two phases of service subject to the server breakdown and delayed repair," Applied Mathematical Modelling, vol. 33, no. 6, pp. 2699-2709, 2009.

[150] K.-H. Wang, D.-Y. Yang, and W. L. Pearn, "Comparison of two randomized policy $M / G / 1$ queues with second optional service, server breakdown and startup," Journal of Computational and Applied Mathematics, vol. 234, no. 3, pp. 812-824, 2010.

[151] I. Dimitriou and C. Langaris, "A repairable queueing model with two-phase service, start-up times and retrial customers," Computers \& Operations Research, vol. 37, no. 7, pp. 1181-1190, 2010.

[152] V. Thangaraj and S. Vanitha, "M/G/1 queue with two-stage heterogeneous service compulsory server vacation and random breakdowns," International Journal of Contemporary Mathematical Sciences, vol. 5, no. 7, pp. 307-322, 2010.

[153] G. Choudhury, L. Tadj, and K. Deka, "A batch arrival retrial queueing system with two phases of service and service interruption," Computers \& Mathematics with Applications, vol. 59, no. 1, pp. 437-450, 2010.

[154] G. Choudhury and L. Tadj, "The optimal control of an $M^{x} / G / 1$ unreliable server queue with two phases of service and Bernoulli vacation schedule," Mathematical and Computer Modelling, vol. 54, no. 1-2, pp. 673-688, 2011.

[155] S. P. Murugan and R. Kalyanaraman, "A vacation queue with additional optional service in batches," Applied Mathematical Sciences, vol. 3, no. 24, pp. 1203-1208, 2009. 
[156] S. P. B. Murugan and R. Kalyanaraman, "A vacation queue with additional optional service in batches," Applied Mathematical Sciences, vol. 3, no. 21-24, pp. 1203-1208, 2009.

[157] R. Sharma, "A bulk arrival queue with server breakdown and vacation under N-policy," in Elec. Proc. Nat. Conf. Eme. Tre. Eng. Tech., vol. 30, pp. 104-107, March 2014.

[158] L. Tadj and J. C. Ke, "A hysteretic bulk quorum queue with a choice of service and optional re-service," Quality Technology \& Quantitative Management, vol. 5, no. 2, pp. 161-178, 2008.

[159] M. Haridass and R. Arumuganathan, "Analysis of a batch arrival general bulk service queueing system with variant threshold policy for secondary jobs," International Journal of Mathematics in Operational Research, vol. 3, no. 1, pp. 56-77, 2011.

[160] J.-C. Ke, "An $M^{X} / G / 1$ system with startup server and $J$ additional options for service," Applied Mathematical Modelling, vol. 32, no. 4, pp. 443-458, 2008.

[161] G. Choudhury and K. Deka, "An $M^{X} / G / 1$ unreliable retrial queue with two phases of service and Bernoulli admission mechanism," Applied Mathematics and Computation, vol. 215, no. 3, pp. 936-949, 2009.

[162] C. S. Kim, S. H. Park, A. Dudin, V. Klimenok, and G. Tsarenkov, "Investigation of the BMAP/G/1/1./PH/1/M tandem queue with retrials and losses," Applied Mathematical Modelling, vol. 34, no. 10, pp. 2926-2940, 2010.

[163] C. Kim, S. Dudin, and V. Klimenok, “The MAP/PH/1/N queue with flows of customers as a model for traffic control in telecommunication networks," Performance Evaluation, vol. 66, no. 9-10, pp. 564-579, 2009.

[164] R. B. Lenin, A. Cuyt, K. Yoshigoe, and S. Ramaswamy, "Computing packet loss probabilities of D-BMAP/PH/1/N queues with group services," Performance Evaluation, vol. 67, no. 3, pp. 160$173,2010$.

[165] Z. Liu and S. Gao, "Discrete-time $\mathrm{Geo}_{1}, \mathrm{Geo}_{2}^{X} / \mathrm{G}_{1}, \mathrm{G}_{2} / 1$ retrial queue with two classes of customers and feedback," Mathematical and Computer Modelling, vol. 53, no. 5-6, pp. 1208-1220, 2011.

[166] C.-H. Lin, J.-C. Ke, H.-I. Huang, and F.-M. Chang, “The approximation analysis of the discrete-time GEO/GEO/1 system with additional optional service," International Journal of Computer Mathematics, vol. 87, no. 11, pp. 2574-2587, 2010.

[167] C. Goswami and N. Selvaraju, "The discrete-time MAP/PH/1 queue with multiple working vacations," Applied Mathematical Modelling, vol. 34, no. 4, pp. 931-946, 2010.

[168] S. K. Samanta and Z. G. Zhang, "Stationary analysis of a discrete-time GI/D-MSP/1 queue with multiple vacations," Applied Mathematical Modelling, vol. 36, no. 12, pp. 5964-5975, 2012. 


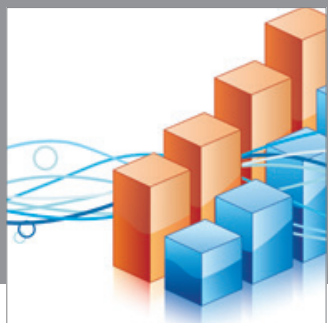

Advances in

Operations Research

mansans

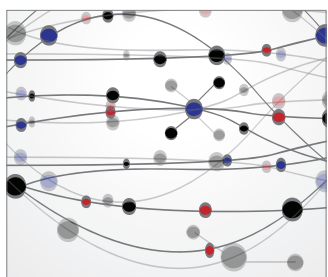

The Scientific World Journal
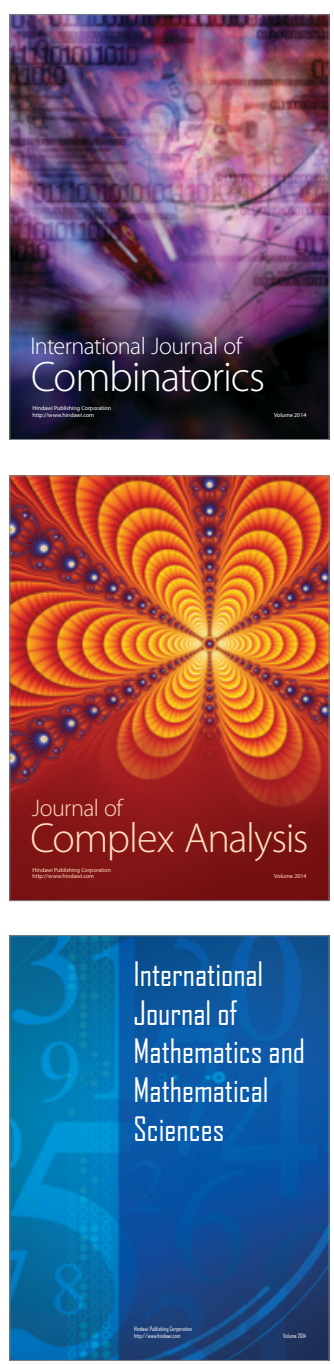
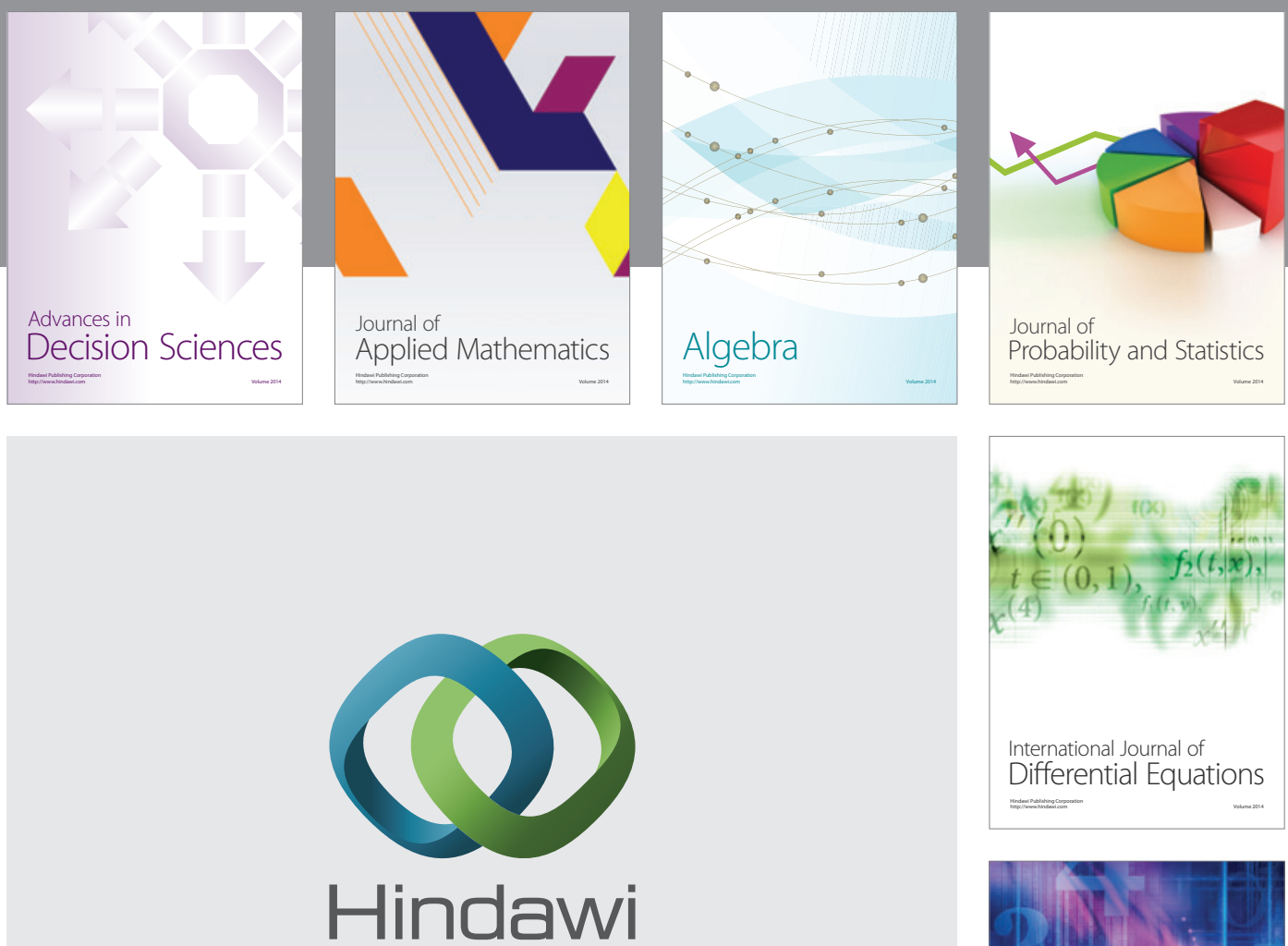

Submit your manuscripts at http://www.hindawi.com
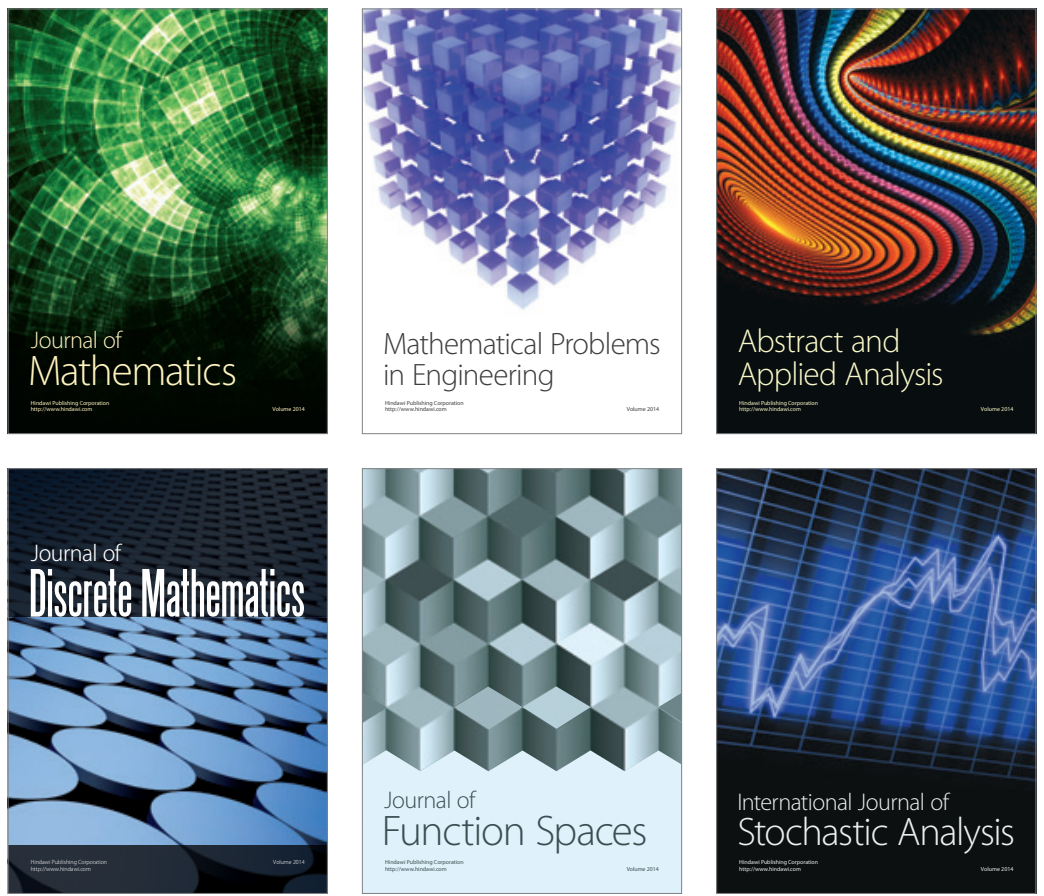

Journal of

Function Spaces

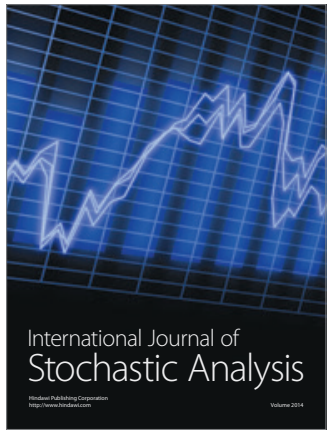

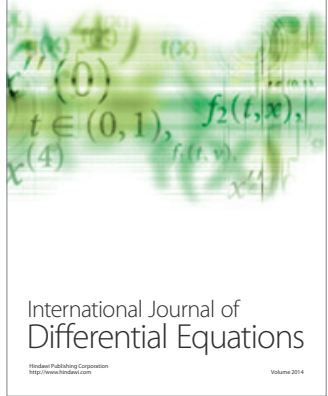
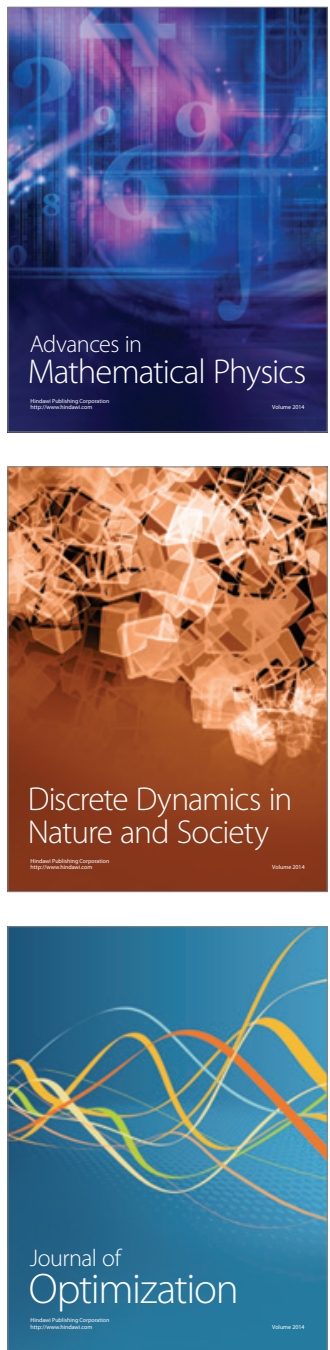